\title{
Enhanced Reliability of Photovoltaic Systems with Energy Storage and Controls
}

Subcontract Report NREL/SR-581-42299

February 2008

D. Manz, O. Schelenz, R. Chandra, S. Bose, M. de Rooij, and J. Bebic GE Global Research Niskayuna, New York 
Enhanced Reliability of

Photovoltaic Systems with Energy Storage and Controls

D. Manz, O. Schelenz, R. Chandra, S. Bose, M. de Rooij, and J. Bebic GE Global Research

Niskayuna, New York

NREL Technical Monitor: Ben Kroposki

Prepared under Subcontract No. ADC-7-77032-01
Subcontract Report NREL/SR-581-42299

February 2008

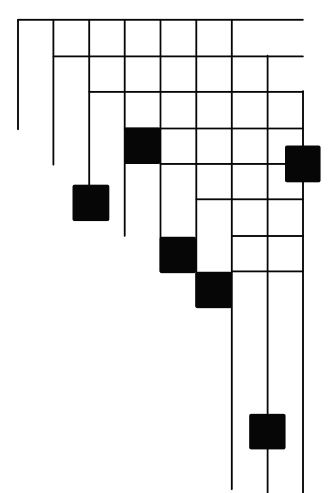




\section{NOTICE}

This report was prepared as an account of work sponsored by an agency of the United States government. Neither the United States government nor any agency thereof, nor any of their employees, makes any warranty, express or implied, or assumes any legal liability or responsibility for the accuracy, completeness, or usefulness of any information, apparatus, product, or process disclosed, or represents that its use would not infringe privately owned rights. Reference herein to any specific commercial product, process, or service by trade name, trademark, manufacturer, or otherwise does not necessarily constitute or imply its endorsement, recommendation, or favoring by the United States government or any agency thereof. The views and opinions of authors expressed herein do not necessarily state or reflect those of the United States government or any agency thereof.

Available electronically at http://www.osti.gov/bridge

Available for a processing fee to U.S. Department of Energy and its contractors, in paper, from:

U.S. Department of Energy

Office of Scientific and Technical Information

P.O. Box 62

Oak Ridge, TN 37831-0062

phone: 865.576 .8401

fax: 865.576 .5728

email: mailto:reports@adonis.osti.gov

Available for sale to the public, in paper, from:

U.S. Department of Commerce

National Technical Information Service

5285 Port Royal Road

Springfield, VA 22161

phone: 800.553 .6847

fax: 703.605.6900

email: orders@ntis.fedworld.gov

online ordering: http://www.ntis.gov/ordering.htm

This publication received minimal editorial review at NREL 


\section{Preface}

Now is the time to plan for the integration of significant quantities of distributed renewable energy into the electricity grid. Concerns about climate change, the adoption of state-level renewable portfolio standards and incentives, and accelerated cost reductions are driving steep growth in U.S. renewable energy technologies. The number of distributed solar photovoltaic (PV) installations, in particular, is growing rapidly. As distributed PV and other renewable energy technologies mature, they can provide a significant share of our nation's electricity demand. However, as their market share grows, concerns about potential impacts on the stability and operation of the electricity grid may create barriers to their future expansion.

To facilitate more extensive adoption of renewable distributed electric generation, the U.S. Department of Energy launched the Renewable Systems Interconnection (RSI) study during the spring of 2007. This study addresses the technical and analytical challenges that must be addressed to enable high penetration levels of distributed renewable energy technologies. Because integration-related issues at the distribution system are likely to emerge first for PV technology, the RSI study focuses on this area. A key goal of the RSI study is to identify the research and development needed to build the foundation for a high-penetration renewable energy future while enhancing the operation of the electricity grid.

The RSI study consists of 15 reports that address a variety of issues related to distributed systems technology development; advanced distribution systems integration; system-level tests and demonstrations; technical and market analysis; resource assessment; and codes, standards, and regulatory implementation. The RSI reports are:

- Renewable Systems Interconnection: Executive Summary

- Distributed Photovoltaic Systems Design and Technology Requirements

- Advanced Grid Planning and Operation

- Utility Models, Analysis, and Simulation Tools

- Cyber Security Analysis

- Power System Planning: Emerging Practices Suitable for Evaluating the Impact of High-Penetration Photovoltaics

- Distribution System Voltage Performance Analysis for High-Penetration Photovoltaics

- Enhanced Reliability of Photovoltaic Systems with Energy Storage and Controls

- Transmission System Performance Analysis for High-Penetration Photovoltaics

- Solar Resource Assessment

- Test and Demonstration Program Definition

- Photovoltaics Value Analysis

- Photovoltaics Business Models 
- Production Cost Modeling for High Levels of Photovoltaic Penetration

- Rooftop Photovoltaics Market Penetration Scenarios.

Addressing grid-integration issues is a necessary prerequisite for the long-term viability of the distributed renewable energy industry, in general, and the distributed PV industry, in particular. The RSI study is one step on this path. The Department of Energy is also working with stakeholders to develop a research and development plan aimed at making this vision a reality. 


\section{Acknowledgments}

The authors would like to acknowledge Ray George from NREL for providing insolation and temperature data for regions of the United States. The authors would also like to acknowledge the contribution of Tom Short from EPRI. Tom provided the GE team with detailed reliability data for two utilities in the United States. The project team would also like to thank the following individuals for their contributions to this study:

1. Jim McMahon of LBL for appliance data models, start/end time estimation.

2. Craig Cornelius for the interaction needed to obtain load modeling data and information.

3. Robert Delmerico of GE Global Research for providing data from studies on load modeling in residential communities.

4. Lawrence Berkley Labs for providing load shapes for several appliances, distinguishing week and weekend days.

5. Patrick G. McElhaney (GE C\&I) for providing data on average per-state home power consumption. 


\section{Executive Summary}

We observed enhanced customer reliability through the management of energy storage systems and photovoltaics (PV) during a utility outage. In an outage, the affected community would intentionally island and meet only its critical load. The timing, duration, and number of customers affected by each outage event were obtained for a single utility in 2005. These data were used to simulate outage events for a community on a distribution feeder. Overall, this technology resulted in a community experiencing fewer outages and outages of shorter duration.

The parameters considered in this analysis include three geographic regions (Golden, Colo., Hanford, Calif., and Sterling, Va.), three community sizes (10 homes, 100 homes, and 1,000 homes), and various combinations of battery capacity ( 0 to $10 \mathrm{kWh}$ ) and solar PV penetration $(0 \%, 5 \%, 10 \%, 30 \%, 50 \%)$. The distribution reliability indices presented in IEEE $1366^{1}$ were adapted to account for the management of energy storage and PV in meeting only the critical loads in each home or community. The enhancement in reliability was quantified in terms of modified reliability indices, which are pertinent to these types of communities:

- Critical SAIDI — average duration of critical load interruptions.

- Critical SAIFI - average number of interruptions per customer.

- Unserved Critical Load (UCL) - annual unserved critical load (kWh) on a circuit.

We observed a significant improvement in these three indices when PV and battery energy storage were deployed at each home within a community. The presence of more than $\sim 5 \mathrm{kWh}$ of battery capacity per home reduced each index to nearly zero (a $100 \%$ reduction). The contribution of PV to the improvement in reliability indices was less significant, contributing to $\sim 25 \%$ reduction in each index at $50 \% \mathrm{PV}$ penetration. The community size and geographic location had a small impact on the overall results.

The following four areas provide a vision for future research:

Load reconfiguration technology - We assumed that the loads in a home/community could reconfigure at the onset on an interruption. Identifying the technology and controls needed to perform this function is critical to achieving enhanced reliability through the use of PV systems.

Customer reliability statistics - Statistics and specific information about which customers are affected during an outage event would enhance the accuracy of the simulation. This information will be needed for both utilities and customers in order to quantify the economic benefit of enhanced reliability due to PV systems. 
Load profile breakdown - A breakdown of the contributions of various appliances to the overall aggregate load of a home (and community) through a year will be needed before customers and utilities invest in home load controls.

Critical loads in communities - Residential customer surveys of appliance usage or appliance feedback to the utility are needed in order to quantify the contribution of each appliance to the total load in a home/community. 


\section{Table of Contents}

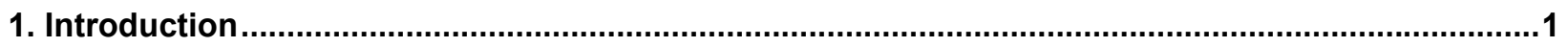

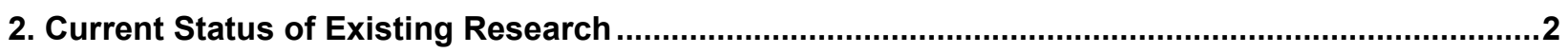

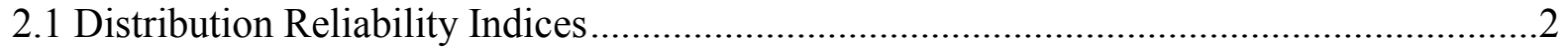

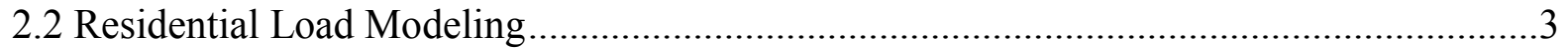

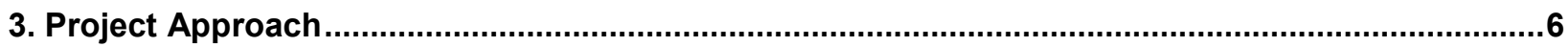

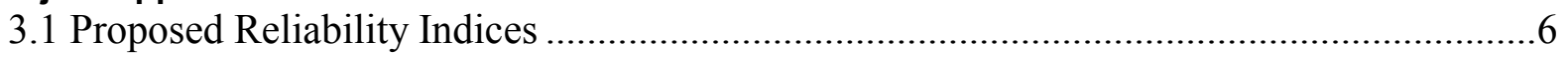

3.2 Distribution Reliability Data............................................................................. 7

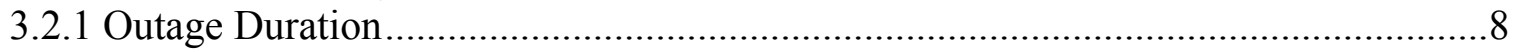

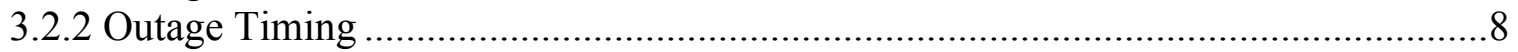

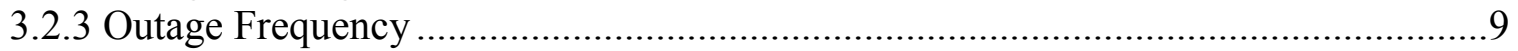

3.2.4 Assumptions and Factors Affecting Reliability ................................................11

3.3 Reliability Modeling Approach and Validation.................................................. 12

3.4 Residential Load Modeling .....................................................................................13

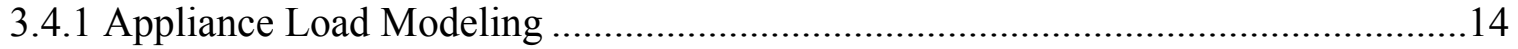

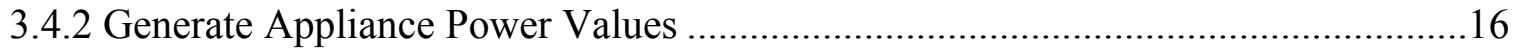

3.4.3 Generate Appliance Runtime Values..................................................................17

3.4.4 Generate Appliance Usage for One Week ...................................................... 19

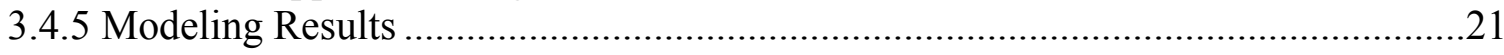

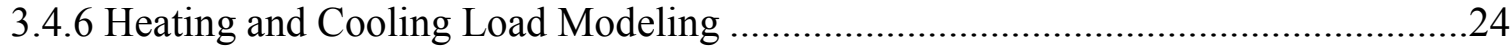

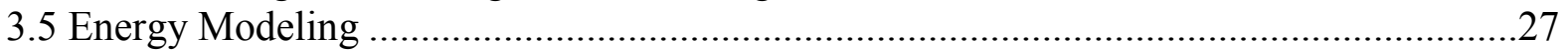

3.5.1 Battery Energy Storage System .....................................................................28

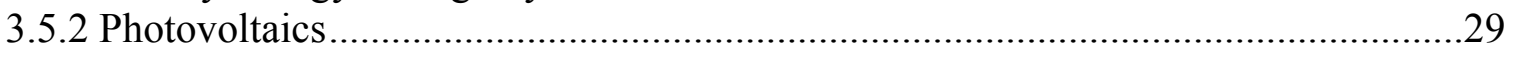

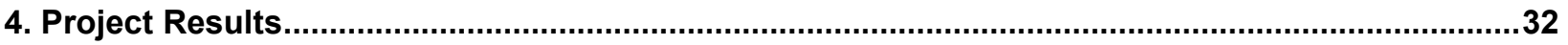

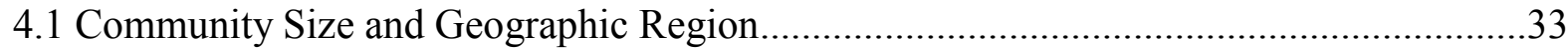

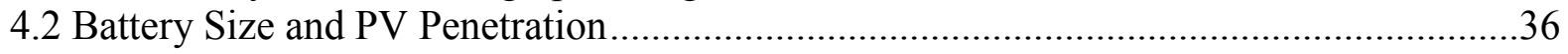

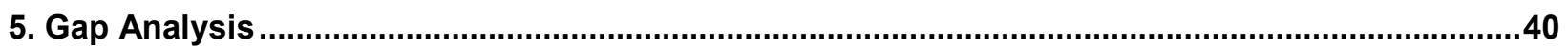

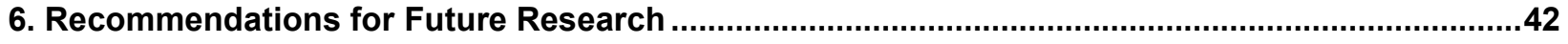

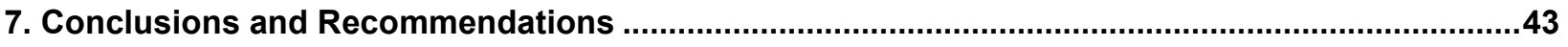

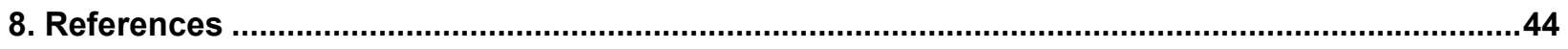




\section{List of Figures}

Figure 1. Percentage of responding companies using indices reporting in 1995 and

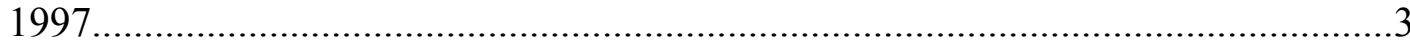

Figure 2. Graphical representation of unserved critical $\mathrm{kWh}$ associated with an outage ..........7

Figure 3. Historical outage duration per outage event for utility A ......................................8

Figure 4. Number of outage events per month for utility A and utility B.............................9

Figure 5. Hourly distribution of outage events for utility A from 1994 to 2003......................9

Figure 6. Utility SAIFI reported in 1990, 1995, and 1997 and sorted by quartile .................10

Figure 7. Number of customers affected based on various outage durations in 2005

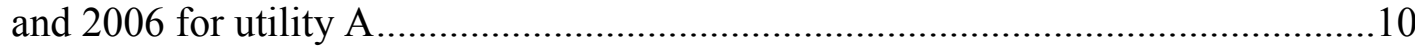

Figure 8. Customers affected during each outage event ................................................11

Figure 9. Weather conditions for each outage event for utility A and utility B ....................11

Figure 10. Outage duration and timing distribution based on 1,000 simulations ....................13

Figure 11. MATLAB appliance load modeling flowchart .............................................15

Figure 12. Appliance power and penetration for a community of 100 homes ........................17

Figure 13. Appliance runtime (in minutes) for a community of 100 homes............................18

Figure 14. Appliance power and runtime for a community of 100 homes .............................19

Figure 15. Appliance scheduling spreadsheet ........................................................20

Figure 16. LBNL-provided chart corresponding to residential drying (left) and residential cooking (right) .................................................................................21

Figure 17. Power consumption by appliance (excluding HVAC) for a community of

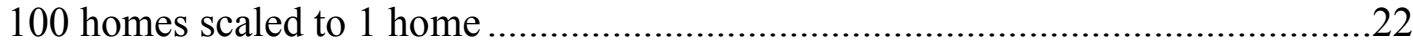

Figure 18. Power consumption per appliance (excluding HVAC) for a single home

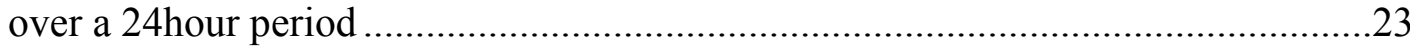

Figure 19. Detailed electric and natural gas consumption over a year...................................26

Figure 20. HVAC power consumption of a Colorado home over one year .............................26

Figure 21. Energy modeling simulation validation .....................................................28

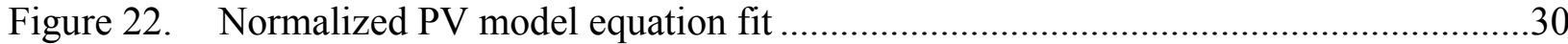

Figure 23. Model validation for Golden, Colo. Data obtained from NREL. ...........................31

Figure 24. Customer reliability for $10 \%, 30 \%$, and $50 \%$ PV penetration, with no battery, for three community sizes in three regions of the United States. .................34

Figure 25. Customer reliability for $10 \%, 30 \%$ and $50 \%$ PV penetration, and a $1-\mathrm{kWh}$ battery, for three community sizes in three regions of the United States. .................35

Figure 26. Critical SAIDI for a 100-home community in Golden, Colo. ...............................37

Figure 27. Critical SAIFI for a 100-home community in Golden, Colo....................................38

Figure 28. Critical kWh unserved for a 100-home community in Golden, Colo.......................38

\section{List of Tables}

Table 1. Appliance Data Input to the MATLAB Model ....................................................15

Table 2. $\quad$ kWh Consumption per Appliance Represented in Figure 17 .............................24

Table 3. Design of Experiments for Reliability Enhancement Modeling ............................32

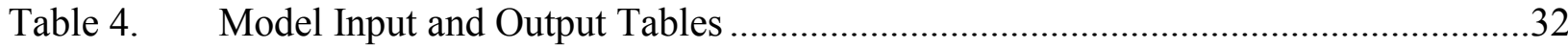




\section{Introduction}

In this study, photovoltaics (PV), load control, and battery energy storage systems were managed in order to enhance energy reliability for the customer. During an interruption, customers within a community are able to intentionally island, reconfigure total loads to only the critical loads, and meet the critical loads by managing PV and energy storage. The objective of this study is to evaluate the reliability improvement associated with this capability. The results of this study can be used to identify the technologies and regulations needed to enable load and energy management in a home or community. Multiple case studies were considered, including three geographic regions, three community sizes, and various combinations of energy storage and PV. In this study, PV penetration is defined as the ratio of the nameplate solar array capacity divided by the maximum 15-min average peak load, within the community, in one year.

Residential load modeling was performed for three regions of the United States and these results were used as an input to the reliability model. We considered adapting the reliability indices presented in IEEE 1366 in order to account for the management of energy storage and PV to meet the critical loads in each home within the community. The enhancement in reliability was quantified in terms of proposed new reliability indices that are pertinent to residential communities containing PV systems with energy storage and controls.

Three community sizes were chosen in order to evaluate the influence of coincidence factors (i.e., a larger community would exhibit a smoother load profile). Three regions were considered because each region has unique annual weather/temperature profiles, and therefore a unique heating, ventilation and air conditioning (HVAC) load profile. Additionally, appliance penetration levels vary from region to region. Fifteen-minute time steps were chosen because no data were available for shorter intervals and additional fidelity would provide computation management challenges.

In order to quantify the enhancement in reliability, the following tasks were performed:

- Reliability Modeling - Random outages were generated based on representative utility data.

- Residential Load Modeling - Total and critical load curves were constructed for individual homes and residential communities.

The reliability model was used to simulate random outages throughout the year. During the outages, the residential-load model reconfigured HVAC and appliance loads to only the critical loads. The architecture of a system that could enable load reconfiguration was not the focus of this study. As a first step, quantifying reliability enhancement will enable the development of a value proposition for such a capability, and may ultimately lead to further technology development. In order to perform this study, we made some key assumptions: (1) a residential home could intentionally island load on PV inverters and breakaway from the grid during an outage, and would be capable of managing starting inrushes, and (2) the circuit protection within the island could be resolved. 


\section{Current Status of Existing Research}

The review of existing research is broken into two sections: distribution reliability and residential load modeling. These two distinct topics provided the basis for quantifying the reliability enhancement.

\subsection{Distribution Reliability Indices}

The IEEE Guide for Electric Power Distribution Reliability Indices (IEEE 1366) was developed in order to summarize relevant distribution reliability indices, outline the methodology for calculating these indices, and highlight the factors that affect the calculation of indices.

In order to understand the details of IEEE 1366, definitions and additional information are needed. In the standard, a long interruption is defined as an event whereby the voltage at the customer's connection drops to zero and does not re-establish automatically. Typically, interruptions in excess of three minutes are referred to as long interruptions, while interruptions of less than three minutes are called short interruptions, ${ }^{2}$ but this definition varies among utilities. Additionally, the term "sustained interruption" refers to a longer interruption, ranging from three seconds in IEEE 1159 to two minutes in IEEE $1250 .^{3}$

The primary distribution reliability indices used for sustained interruptions (outages in excess of five minutes and excluding major event days) are:

- System average interruption frequency index (SAIFI),

- System average interruption duration index (SAIDI), and

- Customer average interruption duration index (CAIDI).

SAIFI describes how often an average customer will experience a sustained interruption (greater than five minutes). Mathematically, this index is defined as:

$$
S A I F=\frac{C l}{N_{T}},
$$

where $C I$ is the number of customers interrupted and $N_{T}$ is the total number of customers served for the area. SAIDI is defined as the total duration of interruption for an average customer over a specific period of time. Mathematically, this index is defined as:

$$
S A I D=\frac{C M I}{N_{T}},
$$

where $C M I$ is the customer minutes interrupted. In terms of load-based indices, the average system interruption frequency index (ASIFI) is often used to measure performance in areas with few consumers and concentrated loads. ${ }^{4}$ Mathematically, ASIFI is defined as: 


$$
A S I F=\frac{\sum L_{i}}{L_{T}},
$$

where, ASIFI is the ratio of total connected kVA of load interrupted and the total connected kVA served.

SAIDI and SAIFI are two of the most common distribution reliability indices used in the industry (see Figure 1).

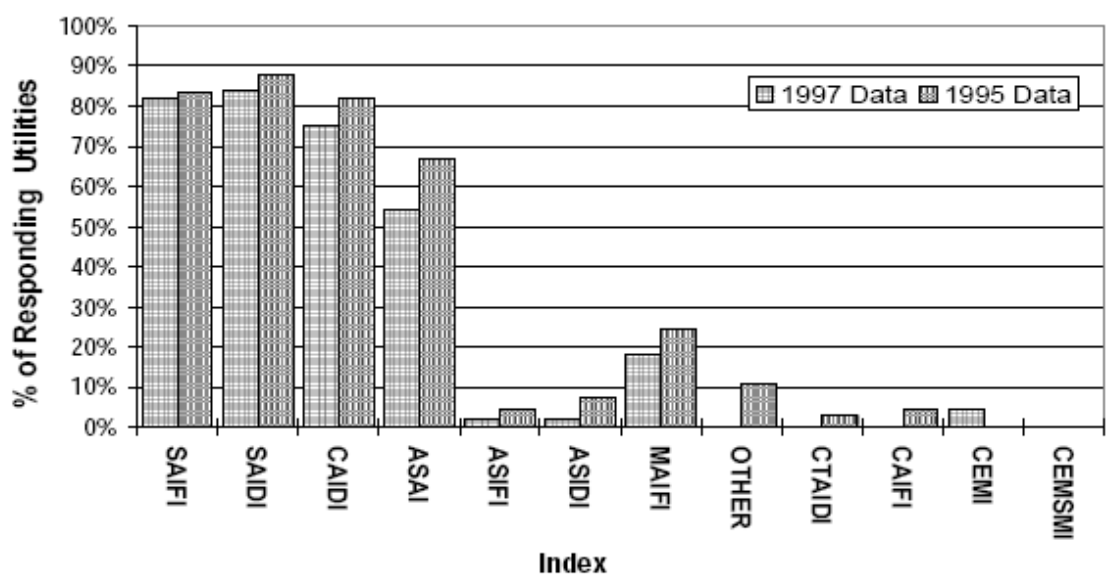

Figure 1. Percentage of responding companies using indices reporting in 1995 and $1997^{5}$

The distribution reliability indices described above are used to quantify sustained interruptions. Short duration outages for some customers, such as hospitals and large industrial customers, can result in complex systems shutting down. The startup of these systems can be costly. In many cases, these customers have installed backup generation or other means of addressing short-duration outages. In particular, it is these types of outages that would benefit from the presence of distributed generation and energy storage in islanded operation. Therefore, a reliability index must not only quantify enhanced reliability for sustained interruptions, but must also quantify enhanced reliability for short-duration outages.

\subsection{Residential Load Modeling}

Taking into account customer data for variable numbers of customers is essential for studying the time evolution of the load in the distribution system feeders. In fact, the electricity consumption of the single residential customer is too variable in time to allow us to obtain a sound estimate of its individual load pattern. The residential load aggregation can be obtained by either working directly at the distribution system level (if the results of measurements carried out on several feeders are available), or resorting to a bottom-up approach in which the aggregated load patterns of single-house customers are computed on the basis of information obtained from real-case investigations on customer behavior, lifestyle, and appliance use. In particular, it is important to assess not only the average value of the aggregated load, but also how its probability distribution varies during the day and as a function of the number of residential customers. Previous studies 
$\left[{ }^{17},{ }^{19},{ }^{20},{ }^{21}\right]$ have shown that the time evolution of the average power, normalized with respect to the total contract power of the customers, has a predictable behavior, especially when the number of customers is relatively high (e.g., over 100). Yet, when the number of customers is low, the possible variations of the load power at any given time are significantly higher and strongly depend on the randomness of the customer composition and lifestyle.

We reviewed a number of articles describing the distribution load profiling techniques. A selected few are discussed in this section. Two main categories of approaches, top-down and bottom-up, were found to exist in most of these articles.

Top-down methods require data collection at the distribution substation. Even when such data are available, this approach does not easily accommodate modeling the impact of demand-response technologies. Bottom-up methods attempt to quantify the drivers for consumption and use Monte Carlo sampling to synthesize an aggregated load profile. Critical inputs are resident demographics, home size, geographic location, season, day of week, time of day, and the number of homes supplied by the feeder.

In Schneider \& Hoad (1992), ${ }^{6}$ researchers applied Monte Carlo sampling to data from a survey of household usage patterns. A diversity function was fit to the data, relating the diversity factor to the number of homes on the feeder. In Lee \& Etezadi-Amoli (1993), ${ }^{7}$ the authors made some general notes about coincident and diversity factors. Coincident factors differ by user type. Industrial and commercial users have higher coincident factors during the day while residential coincident factors have evening peaks. In addition, coincident factors tend to be higher during peak load. Finally, diversity factors were found to be similar for homes with electric and non-electric heating.

While focused on methods to produce short-term residential forecasts, elements of Noureddine et al. (1992) ${ }^{8}$ apply to longer-term modeling. Loads are split between weather- and non-weather-dependent categories. Weather-dependent loads are modeled with a physics-based model while non-weather-dependent loads are quantified with an autoregressive model. Limitations of models like DOE2 are discussed - such models are house specific and ignore random usage patterns.

In Capasso \& Grattieri (1994), ${ }^{9}$ bottom-up modeling was conducted using cross-sectional (time of day) and longitudinal (day of week) use surveys as well as census data describing regional proclivities. In Carpaneto \& Chicco (2006) ${ }^{10}$ researchers found that the load profile for feeders with more than 100 homes has a predictable behavior. However, as the number of homes decreases, the profile is significantly impacted by the number of customers and the randomness of customer use patterns. A number of probability functions were fitted to the aggregated load profile. The gamma function was found to be most appropriate for extra-urban homes.

We reviewed many other articles to decide the appropriate tools for the modeling work. While the appliance load data can be built upon some existing data sources $\left[{ }^{11},{ }^{12}\right]$ using simple spreadsheet-based calculations, a more detailed thermal model of the home is necessary to understand the HVAC loads. Drury et al. $(2005)^{13}$ provided an overview of 
a report that provides up-to-date comparisons of the features and capabilities of twenty major building energy simulation programs. The comparison is based on information provided by the program developers in the following categories:

- General modeling features,

- Zone loads,

- Building envelope and day-lighting and solar,

- Infiltration, ventilation and multi-zone airflow, renewable energy systems,

- Electrical systems and equipment,

- HVAC systems,

- HVAC equipment,

- Environmental emissions,

- Economic evaluation,

- Climate data availability, results reporting; validation, and

- User interface, links to other programs, and availability.

After careful investigation of all these tools, and based on prior experience of available resources, DOE2.2 was chosen to analyze the heating and cooling loads of a home. As DOE2.2 requires extensive inputs to perform a comprehensive simulation of all the loads, the loads, which do not have a significant impact on heating and cooling, are excluded from this model and were handled in the spreadsheet-based model. This approach is described in Section 3.4 in more detail. 


\section{Project Approach}

In order to quantify the enhancement in reliability we needed to identify relevant distribution reliability indices that would accurately reflect reliability improvements and offer a benchmark to reliability improvements. Once identified, distribution reliability data (duration, timing, and the number of customers affected in each outage) were used to construct a reliability model that could simulate random outages within a community. Finally, a residential load model was developed. This model consists of total and critical HVAC and appliance load data, in 15-minute intervals, for three regions and three community sizes. During an outage, total load (for a given community in a given region) is reconfigured to form the critical load, where management of PV and energy storage meets this load. Outage data were generated by the reliability model, while load data were generated by the residential load model.

\subsection{Proposed Reliability Indices}

We anticipate that managing loads, PV, and energy storage will reduce (or perhaps eliminate) the number of outages a customer experiences and will reduce the duration of each outage a customer experiences. Since load control will also allow customers to differentiate between critical and non-critical loads in their homes, the reliability indices should be revised to account for a customer's willingness to shed non-critical loads during a system interruption. Therefore, the following revisions to SAIDI and SAIFI are used in this study:

- Critical SAIFI is defined as the average number of critical load interruptions experienced on a circuit.

- Critical SAIDI is defined as the average duration of critical load interruptions experienced on a circuit.

- Unserved Critical Load (UCL) is a proxy for ASIFI, defined as the annual unserved critical load $(\mathrm{kWh})$ on a circuit.

In Figure 2, area "A" represents the total $\mathrm{kWh}$ unserved during an outage and area "B" represents the critical $\mathrm{kWh}$ unserved duration an outage. A PV system with energy storage and load controls will reduce the unserved critical $\mathrm{kWh}$, shown as area "C". This study will quantify the enhanced reliability that PV systems with energy storage and load controls offer to residential communities based on these three indices. 


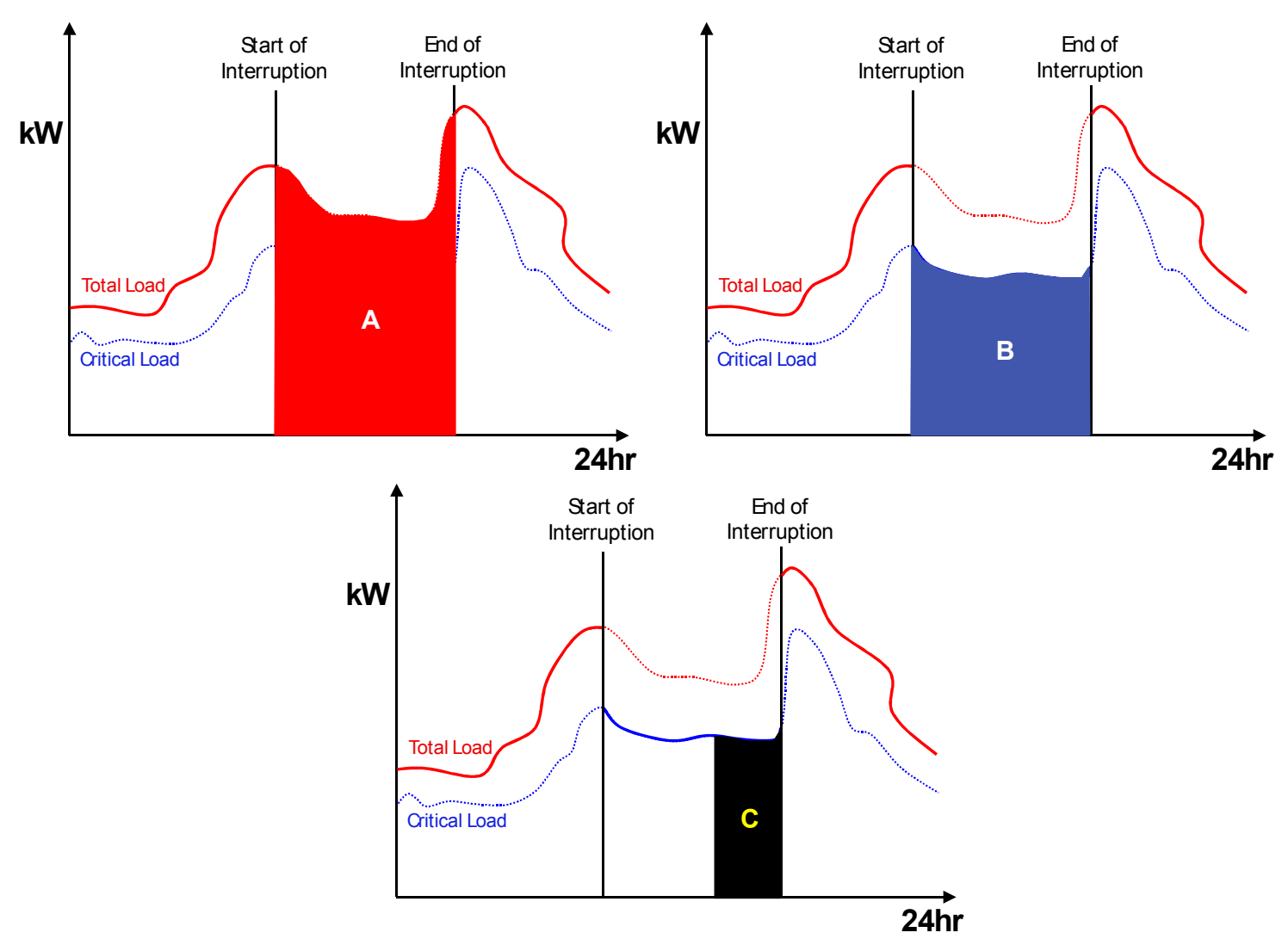

Figure 2. Graphical representation of unserved critical kWh associated with an outage

\subsection{Distribution Reliability Data}

Reliability data for two utilities were provided by the Electric Power Research Institute (EPRI). ${ }^{14}$ Utility A is a small utility (fewer than 200,000 customers) located in the northeastern United States. Utility B is a larger utility (greater than 800,000 customers) located in the southeastern United States. Generally, utilities collect data for outages in excess of five minutes. The data provided includes all outages in excess of five minutes (including major event days). Outage events were determined by supervisory control and data acquisition (SCADA) measurement or by customer reporting. The data for utility A were provided with hourly time stamps for each event from 1994 to 2003, and daily time stamps for each event from 2004 to the end of 2006. Data were provided for utility B (with daily time stamps for each event) for the year 2005 only.

The reliability statistics chosen for this study were based on data from utility A. With more than 20,000 events in 10 years, utility A offered a significant database, containing 10 years of outage event data (outage duration, circuit affected, number of customers affected, weather condition, number of customers per circuit, etc.) with hourly time stamps for nine years of outage events. Although focusing on the distribution reliability performance of a single utility does not ensure that an "average" utility was considered in this study, the vast database of outage information was thought to provide the study with the best statistical data from a single data source. This ensures that outage durations obtained from one study are not intermixed with frequency data from another study. The 
model has been developed to incorporate distributions of outage duration (per event) and customers affected (per outage duration) as an input. Therefore, if additional data is available, additional model runs can easily be performed.

\subsubsection{Outage Duration}

Based on the number of outage events presented in the data for utility A, an outage duration histogram was generated for two consecutives year (see Figure 3).

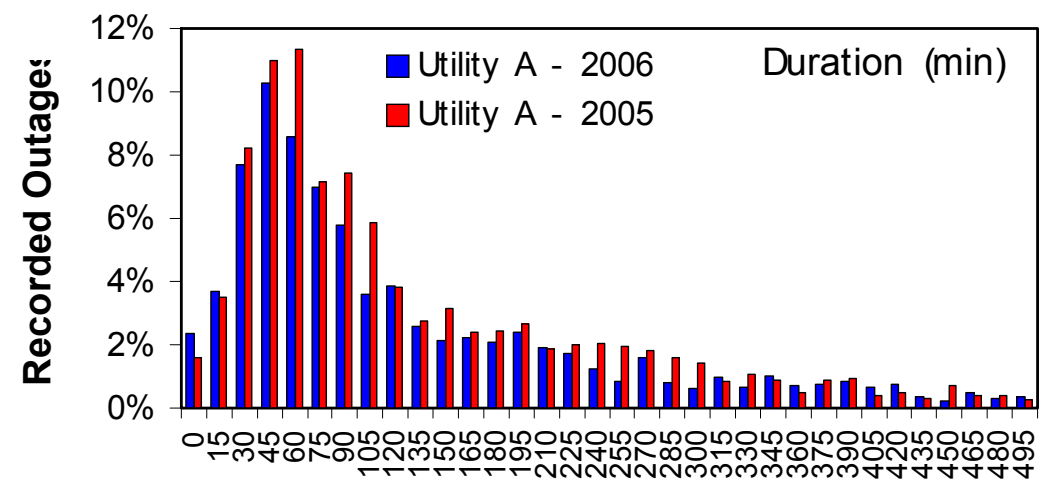

Figure 3. Historical outage duration per outage event for utility $A$

Most outage durations in 2005 and 2006 were shorter than 100 minutes, though some outages were much longer. Note that each outage event affected a different number of customers.

\subsubsection{Outage Timing}

Based on the data for utility A, outages were not evenly distributed throughout the year. This trend was observable over various years of operation. The number of outage events per month in 2005 is shown for utility A and utility B in the top of Figure 4. Additionally, the number of outage events for four consecutive years at utility A is shown in Figure 4. The correlation of outage frequency to time of year can be easily observed. Based on the data provided for utility A, we examined the number of outage events over a 24-hour period (see Figure 5). These data are considered on an outage event basis, which treats each outage event as equal, independent of the number of customers affected. 


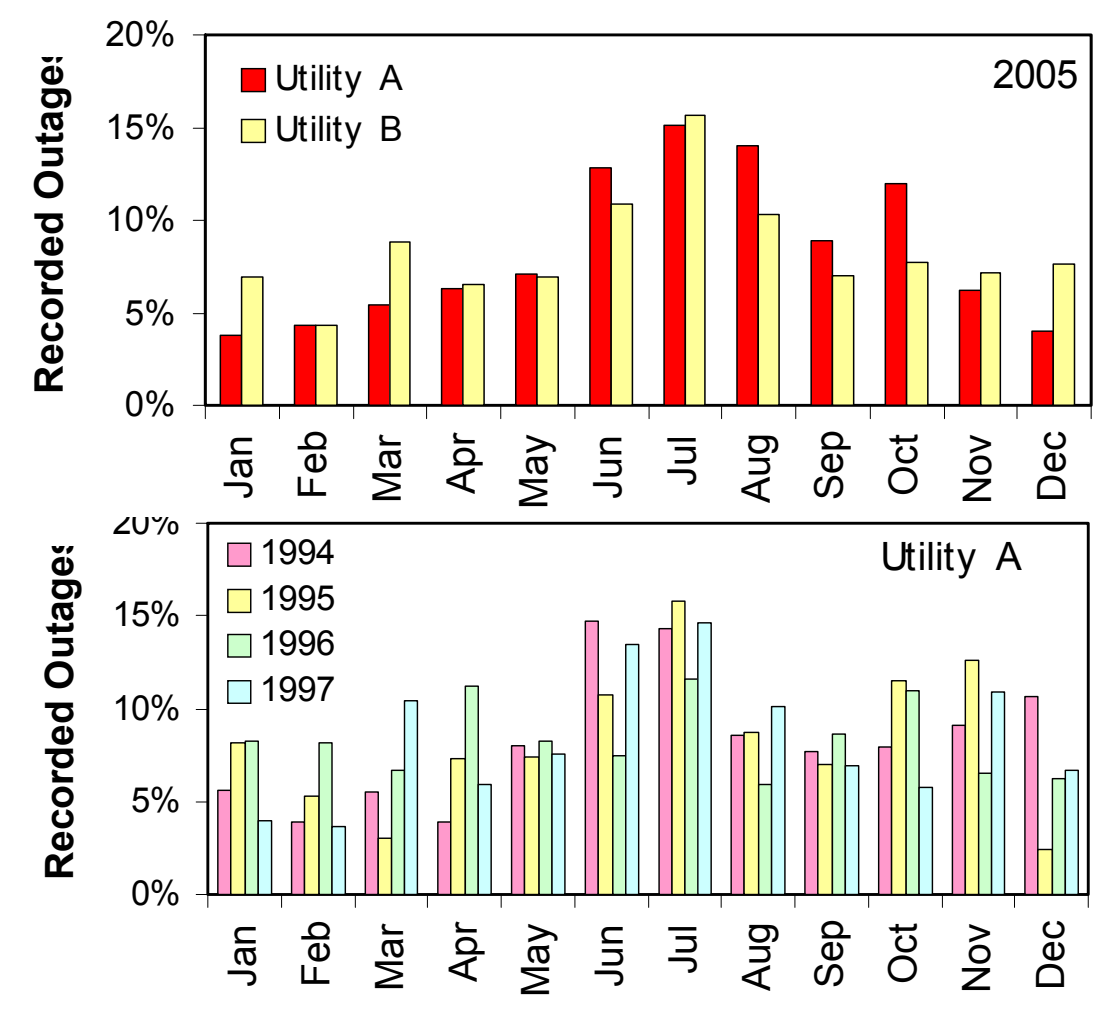

Figure 4. Number of outage events per month for utility A and utility B

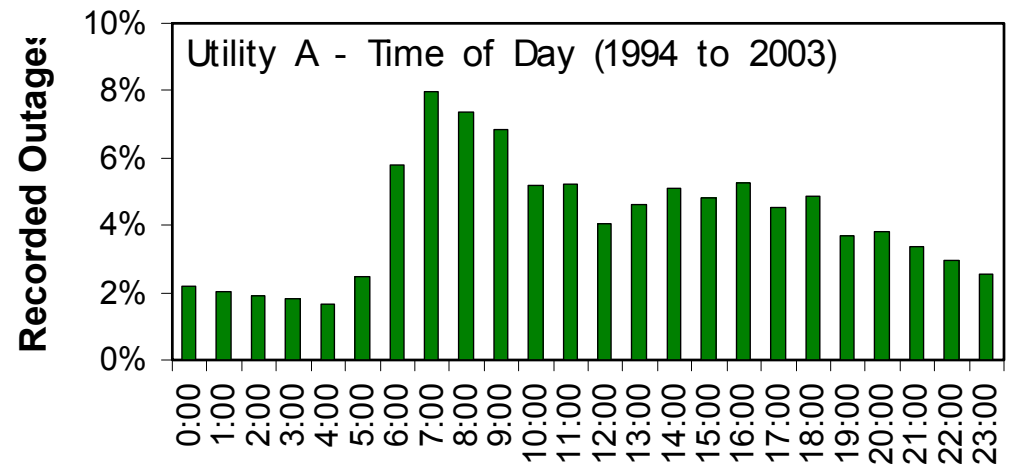

Figure 5. Hourly distribution of outage events for utility A from 1994 to 2003

\subsubsection{Outage Frequency}

The SAIFI data is widely available for many utilities (see Figure 6), but SAIFI (number of outages experienced per customer) is an aggregate of outage frequency data and does not provide enough information to determine the distribution of outages experienced by each customer in a utility. Since there is a correlation between the number of customers affected by an outage event and the duration of the same outage event (see Figure 7) it was necessary to account for this relationship in order to validate the model's results against the SAIDI and SAIFI for utility A. 


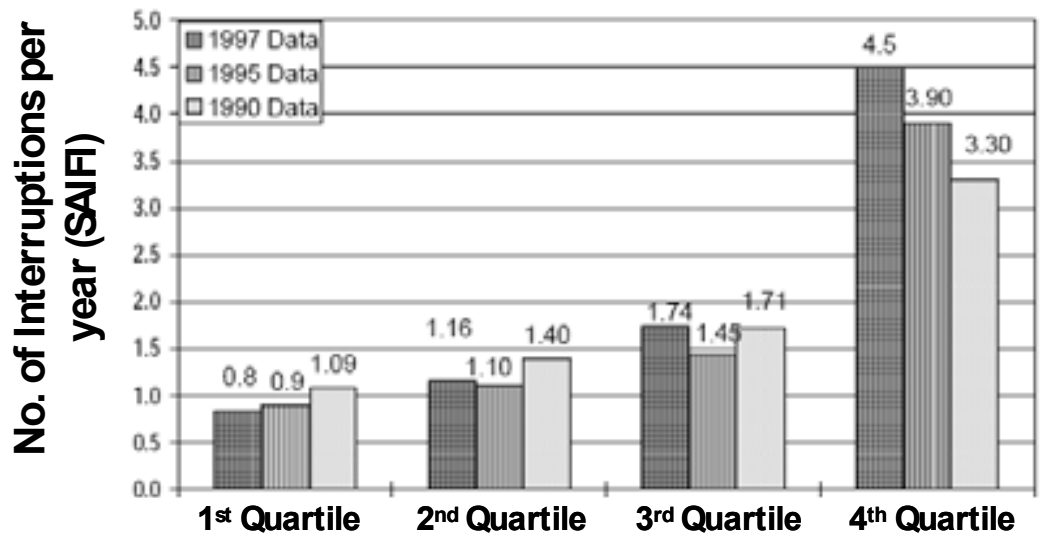

Figure 6. Utility SAIFI reported in 1990, 1995, and 1997 and sorted by quartile ${ }^{15}$

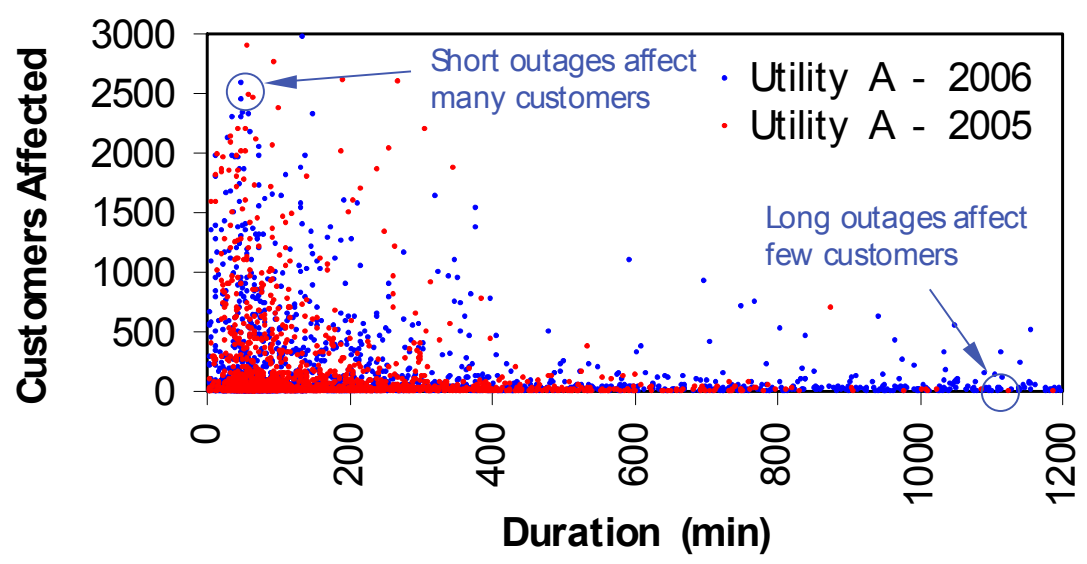

Figure 7. Number of customers affected based on various outage durations in 2005 and 2006 for utility A

Based on the relationship between the customers affected and the outage duration, the energy systems model chose the outage duration and chose the number of customers affected based on the statistical distribution of customers affected for each outage (Figure 7). This was done to replicate the number of outage events experienced by utility A rather than replicate individual customer reliability throughout the year. Therefore, SAIDI and SAIFI for utility A were used to validate the simulation. Based on the data for utility A and utility $\mathrm{B}$, the number of customers affected by each outage event highlights a similar relationship (see Figure 8). 

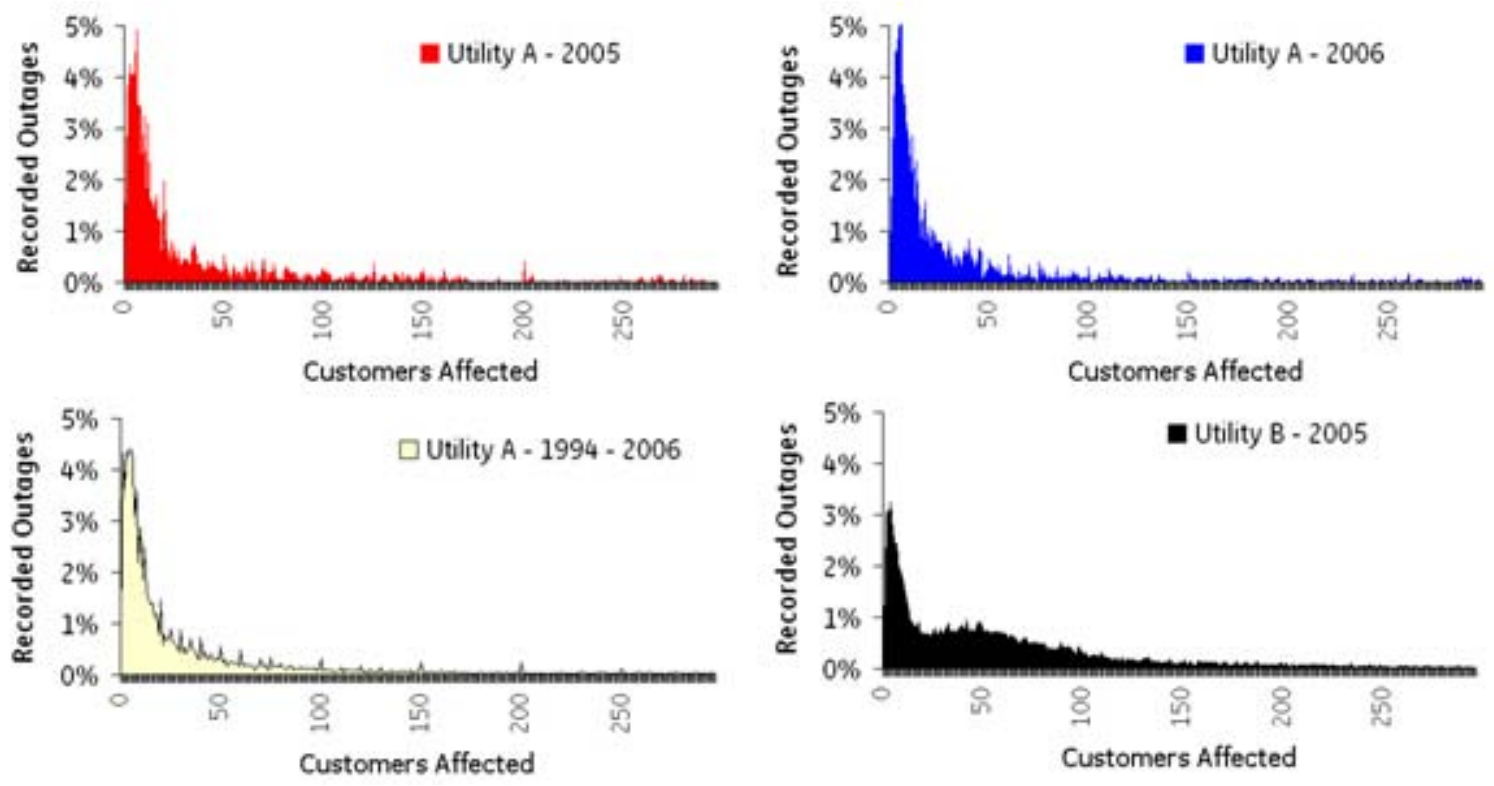

Figure 8. Customers affected during each outage event

\subsubsection{Assumptions and Factors Affecting Reliability}

Many assumptions were made in order to simulate outage timing and duration. The lack of data on short-duration outages (less than five minutes) and the need to limit the size of the model, made it difficult to model short-duration outages. Since the model is discretized into 15-minute intervals, outages are rounded to the nearest 15-minute interval. This study will be unable to account for some factors, such as the correlation between lower than average solar insolation levels and poor weather conditions due to a storm. This factor presumably increases the probability of an outage. Similarly, the correlation between higher ambient temperatures (which leads to lower PV efficiency) on a "hot" day and increased outages due to hot weather will not be captured in this study. The weather observed during each outage event is shown for utility B in 2005 and utility A in 2005 and 2006 (see Figure 9).
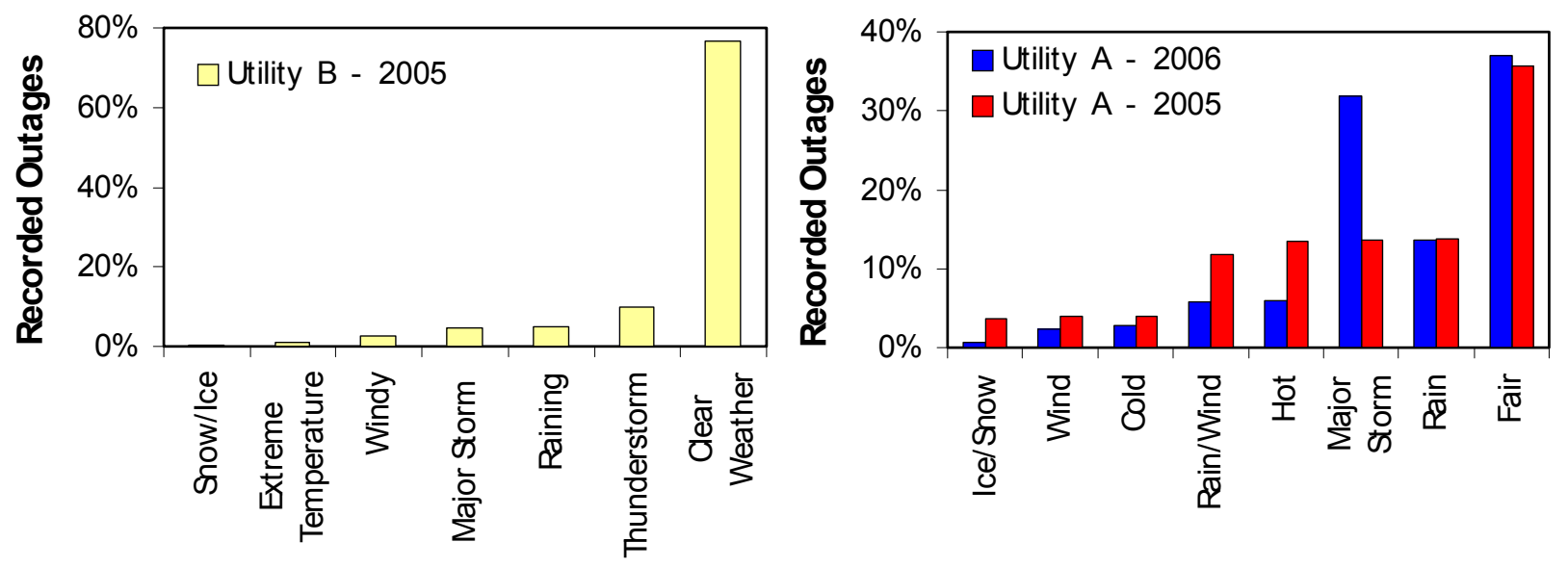

Figure 9. Weather conditions for each outage event for utility A and utility B 
The reporting of weather conditions is a subjective measure. Utility A and B used similar, though not identical, labels of weather condition.

\subsection{Reliability Modeling Approach and Validation}

In order to generate outage statistics for an outage event, we used statistical duration and timing data from utility A. The following list highlights the modeling approach:

1. For a single event, the outage duration was chosen from a bin of outage durations (15 minutes per bin) based on the discrete distribution of outage events in utility A in 2005 (see Figure 3).

2. The outage duration was chosen randomly from within the selected bin and rounded to a multiple of 15 minutes.

3. The month in which the event occurred was selected based on the discrete monthly distribution of outage events for utility A in 2005 (see Figure 4).

4. The day in which the event occurred was chosen randomly from within the month.

5. The hour in which the event occurred was selected based on the discrete hourly distribution of outage events for utility A from 1995 to 2003 (see Figure 5).

6. The event was placed on the first 15-minute interval of that hour.

7. The number of customers affected is chosen based on the relationship between the outage duration and the number of customers affected in utility A (see Figure 7).

8. A single simulation consists of an outage duration, timing, and number of customers affected. This is performed 1,800 times to replicate the number of events experienced by utility $A$ in 2005 .

Based on this approach, 1,000 simulations of a single outage event were performed. The results are summarized in Figure 10. A good match between the results shown below and the reliability data from utility A was observed. 

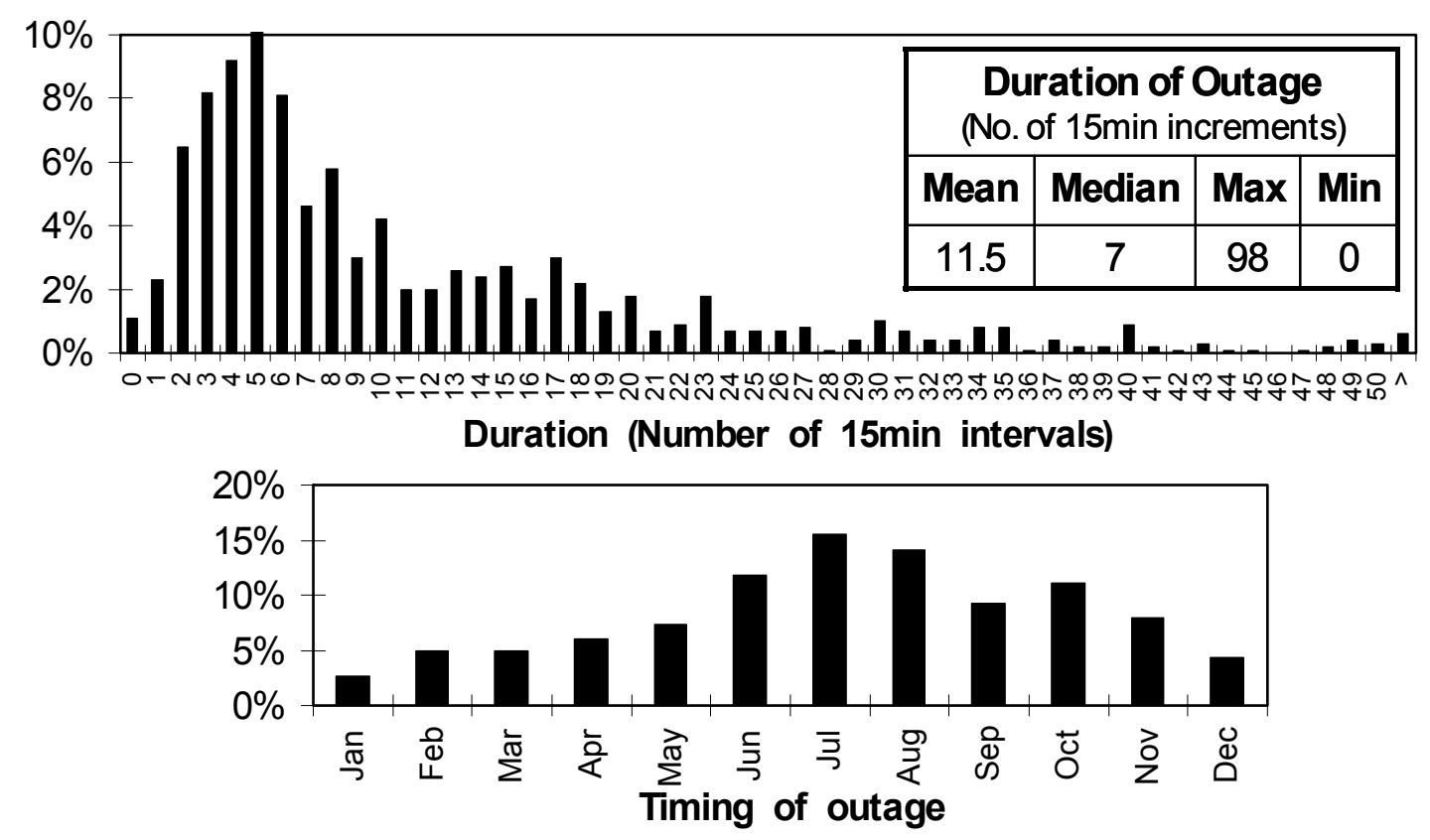

Figure 10. Outage duration and timing distribution based on 1,000 simulations

Each outage event was input into the energy systems model and the reliability indices (described earlier) were quantified with and without the PV, energy storage, and load control system.

Based on this approach, the average of more than 100 simulations reveals that the simulation SAIDI replicates the actual SAIDI, within 5\%, for utility A in 2005. Additionally, the simulation SAIFI compares within 1\% of the actual SAIFI for utility A in 2005. Any discrepancy between the SAIDI/SAIFI for utility A and the simulation is associated with the statistical sampling of the number of customers affected by an event (equally probable) based on the outage duration for the event.

\subsection{Residential Load Modeling}

As described earlier, load shaping of residential end-users is a highly complex task; a household's energy usage is intimately linked to lifestyle-related factors that are extremely subjective and not easily defined. Furthermore census studies attempting to document this behavior don't fully resolve the problem, because they fail to consider the random variability of the demand.

The residential model is divided into two sections:

1. Matlab-based model for the top rated appliances and lighting

2. DOE 2.2 model for the heating and cooling loads.

The following two subsections describe these two approaches in more detail. 


\subsubsection{Appliance Load Modeling}

A bottom-up approach is used to model electrical appliance loads in the home. This method models each appliance's behavior individually, allowing for a level of granularity that provides insight into the behavior of individual homes and power consumption per appliance. Furthermore, being aware of what each appliance is doing at all times enables load-shedding, allowing for continued operation of critical loads while shedding all noncritical loads, thus lowering the overall power consumption of each home. For the purposes of this report, the critical loads were lighting, refrigeration, and baseline power consumption, a definition of which will follow.

The model is composed of five appliances and lighting. Appliances were chosen by their popularity within the community, ${ }^{16}$ frequency of use, and power consumption. ${ }^{17}$ Once these values were understood, a statistics-based model assigned appliances, power values, and runtimes to each home in the community and dispersed the use of the assigned appliances throughout a day. The dispersion of appliance use throughout a day is modeled with help from Lawrence Berkley National Labs (LBNL) data, ${ }^{19}$ which provide an individualized appliance usage profile over a twenty-four hour period. Furthermore, since this model is limited to five appliances, the baseline power consumption is added to each home in the community to account for most of the residential electrical loads, which are not modeled. The baseline power curve has a bimodal distribution with its peak load located during the hours of greatest electrical activity. The baseline power curve also degrades during the early hours of the morning when most of the community is expected to be sleeping.

For validation purposes, power consumption per appliance was cross checked against yearly expected consumption rates published by the Department of Energy (DOE) on Energy Guide labels and other similar sources. Furthermore, total power consumption throughout the year (including HVAC) was cross-checked against U.S. state average power consumption provided by an internal GE report. The weekly power consumption per appliance and yearly overall power consumption per home data were used to validate the model.

The model is implemented in the computational mathematics program MATLAB. Inputs to the model are read from a Microsoft Excel file and from direct input from the user (Figure 11). The Excel file contains appliance values for penetration into the community, electrical load range, use time, and variability in use start time (Table 1) where "penetration" refers to the percentage of customers in the community who own that appliance. This model only takes into account appliances that are predominantly electric; therefore appliances such as gas dryers were not considered. Furthermore, there are cases in which an appliance will have a greater than $100 \%$ penetration, most commonly observed in refrigerators. Typically $10 \%$ of homes will have a second refrigerator or standalone freezer. However, to reduce the complexity of the model, a maximum of $100 \%$ penetration was set per appliance. The impact of multiples of an appliance remains to be evaluated. 


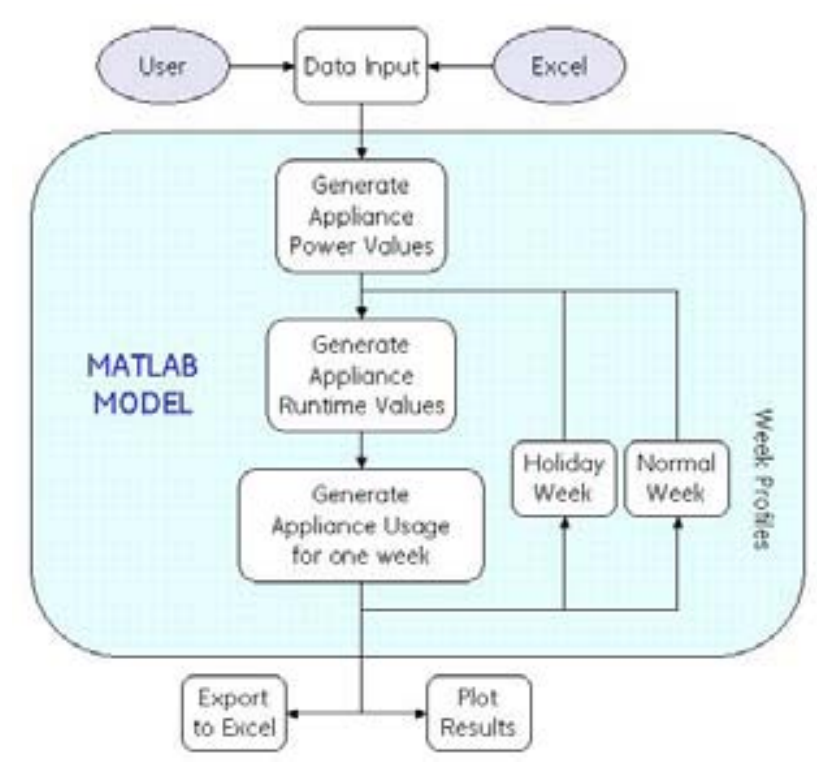

Figure 11. MATLAB appliance load modeling flowchart

Also labeled in Table 1 are Low-/High-End Loads, which indicate the low- and high-end bounds of power consumption, in Watts, for each appliance being modeled. Section 3.4.2 further elaborates how each appliance is assigned a specific value. "Run Time Low/High" indicates low- and high-end bounds of appliance operation time; these values indicate a fraction or multiples of 15-minute intervals for which the appliance is in continuous operation. Section 3.4.3 further explains how these values are determined. Lastly, "Start Time Variability" is the standard deviation, in minutes, of the time when the appliance comes on, allowing community usage to be spread about a time continuum; this concept is further explained in section 3.4.4.

Table 1. Appliance Data Input to the MATLAB Model

\begin{tabular}{|l|c|c|c|c|c|c|}
\hline \multicolumn{7}{|c|}{ Hanford, California } \\
\hline Appliance & $\begin{array}{c}\text { Penetration } \\
\text { (\%) }\end{array}$ & $\begin{array}{c}\text { Low End Load } \\
\text { (Watts) }\end{array}$ & $\begin{array}{c}\text { High End Load } \\
\text { (Watts) }\end{array}$ & $\begin{array}{c}\text { Run Time Low (15 } \\
\text { min) }\end{array}$ & $\begin{array}{c}\text { Run Time High (15 } \\
\text { min) }\end{array}$ & $\begin{array}{c}\text { Start Time } \\
\text { Variability } \\
\text { (Minutes) }\end{array}$ \\
\hline Refrigerator & 100 & 400 & 600 & 0.10 & 0.50 & 60 \\
\hline Dishwasher & 55 & 1200 & 1400 & 3.00 & 5.00 & 60 \\
\hline Washer & 68 & 400 & 600 & 4.00 & 6.00 & 840 \\
\hline Dryer & 35 & 4500 & 5500 & 4.00 & 8.00 & 840 \\
\hline Range & 37 & 2400 & 5000 & 1.00 & 4.00 & 120 \\
\hline Lights & 100 & 400 & 1000 & 1.00 & 10.00 & 60 \\
\hline
\end{tabular}

The direct input from the user consists of the community size, which is a number representing the number of homes to be simulated. As the community size grows, the total power consumption for the community becomes increasingly smooth. If the community size is small (e.g., 10 homes) the total power consumption for the community is more jagged as individual appliances can be seen turning on and off. 
Based on these model inputs, a virtual community of electric loads is generated. The simulation outputs the temporal usage of appliances and lighting. The following sections further describe the generation of the community and parameters for operation.

\subsubsection{Generate Appliance Power Values}

Once a community size has been chosen, each home is provided with electric appliances. It is important to note that not all appliances of the same type are equal in their power consumption. Therefore, to accommodate this factor, a published range of possible power consumptions for each appliance is uniformly sampled to achieve variation within the community. Furthermore, not every home in the community is assigned every electrical appliance. Penetration of an electrical appliance into a particular community is determined by regional census data provided by the DOE Energy Information Administration (EIA). This helps account for homes that do not, for example, have a dishwasher and use a gas range and/or dryer. Therefore, some homes will have every appliance whereas other homes may only have a refrigerator and lights in addition to the baseline power consumption. Figure 12 represents the five appliances and lighting for a community of 100 homes. We can see that the refrigerator and lights are present in every home throughout the community whereas the other appliances have varying degrees of penetration; for example, in this community $67 \%$ of the homes have an electric range. Once the algorithm has finished assigning appliances to every home in the community, these values are then saved and remain fixed for the remainder of the simulation.

To further improve the accuracy of the model, some parameters should be further researched and optimized. One of these parameters is the purchasing habits of consumers; who may prefer a particular brand and/or cost. This results in a normal rather than uniform distribution of power consumption. Furthermore, this model does not take into account consumer preference variation across the different regions modeled; only appliance penetration per region is accounted for. Finally, the variation of power consumption during an appliance's operation is neglected, and is replaced by a constant rate of power consumption. After completing this step the model moves to generating runtimes for each appliance in every home of the community. 

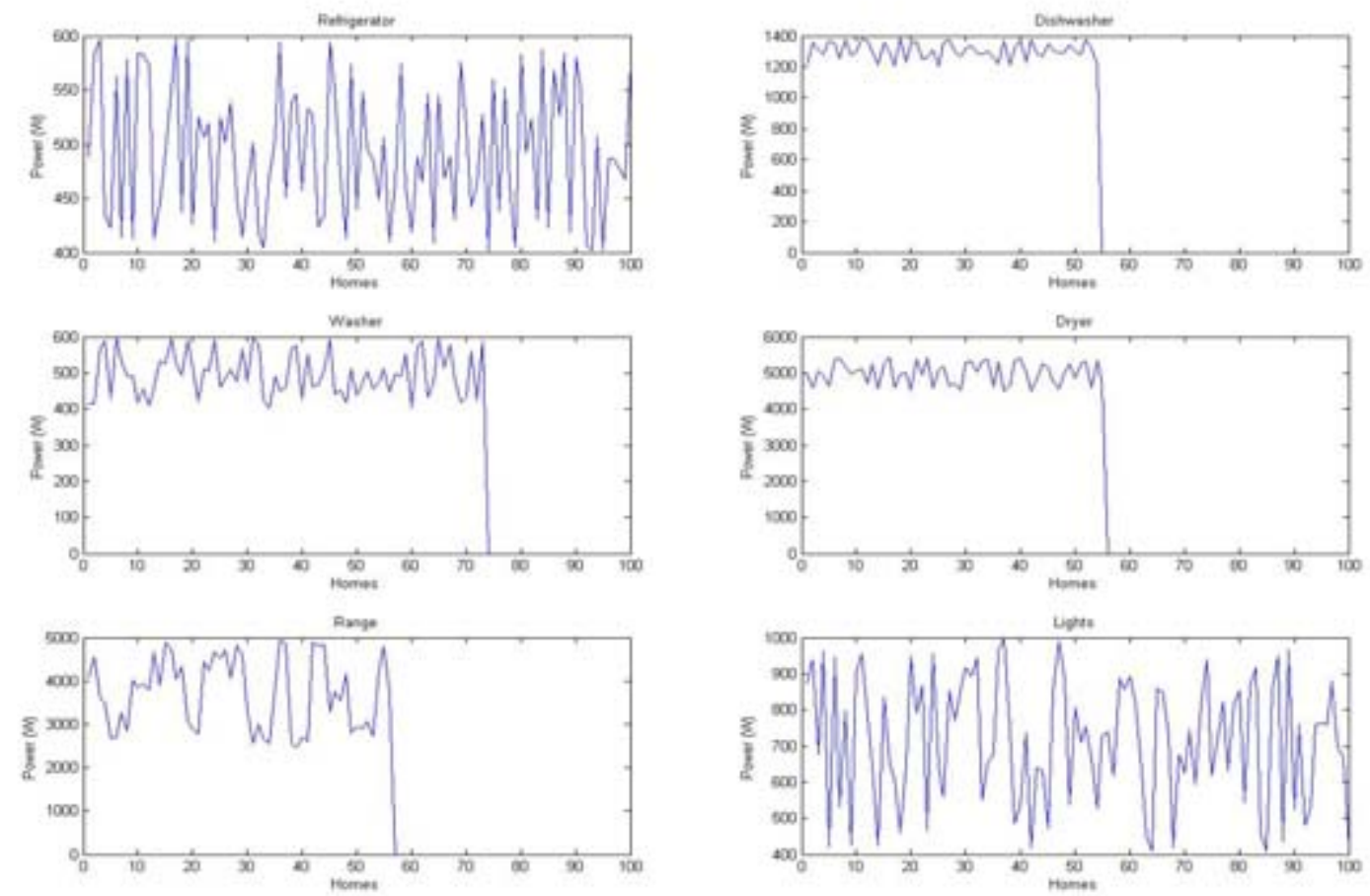

Figure 12. Appliance power and penetration for a community of 100 homes

\subsubsection{Generate Appliance Runtime Values}

Before a typical utilization time for an appliance can be calculated, it should be confirmed that the census data, which provides appliance power and total usage time over one month, agrees with the Energy Guide yearly totals. For example, a dishwasher is reported to be in operation 8 to $40 \mathrm{hr}$ per month ${ }^{17}$. The following can be calculated:

$$
A v g=\frac{1200 \mathrm{~W}+1400 \mathrm{~W}}{2} * \frac{8 \frac{\mathrm{hrs}}{\mathrm{mo} .}+40 \frac{\mathrm{hrs}}{\mathrm{mo} .}}{2} * \frac{12 \text { months}}{\text { year }}=\frac{374.4 \mathrm{kWh}}{\text { year }}
$$

Where the first factor is the average dishwasher power consumption, the second factor is the average use in hours per month. Lastly, these factors are multiplied by months in a year to obtain the yearly kWh usage. The results compare well with an average 323.3 $\mathrm{kWh}$ per year expected consumption. ${ }^{18}$ Using the 8 to $40 \mathrm{hrs}$ of operation per month, a daily usage time is calculated, assuming a thirty-day month. This last operation results in a range of daily "ON" times for each appliance. It is important to consider that some appliances operate one or multiple times an hour and others operate once to multiple times a week, such as the washer and dryer. At this point, the model uniformly samples these ranges, assigning each appliance in the community an individualized runtime. Furthermore, all runtime values are regenerated every week for further variability. As an example, Figure 13 is a histogram graph illustrating binned runtimes and the corresponding number of homes for which that runtime applies. 
The model does not take into consideration how appliance runtimes change throughout the year. Furthermore, there is no correlation between appliance power usage and runtime, so a $5.5 \mathrm{~kW}$ clothing dryer could run for up to two hours and a $4.5 \mathrm{~kW}$ dryer could run for only one hour. Lastly, each selection of runtimes is uniformly chosen from the range of runtimes. This is an assumed behavior and it may not be an accurate representation of consumer habits.

Once appliance power consumption and runtimes are set, a visual check is performed to avoid any outliers (see Figure 14). Furthermore, the figure illustrates many runtimes at zero power. This was done to simplify the model; every home is given runtimes for every electrical appliance within it, whether it exists or not, but the product of these two will not contribute to the overall $\mathrm{kWh}$ consumption for the home if the appliance power value is $0 \mathrm{~W}$.

At this point the MATLAB model has generated a community with electrical appliances and runtimes for each. The next step is to describe the procedure used to schedule appliances throughout the week based on the community's behavior.
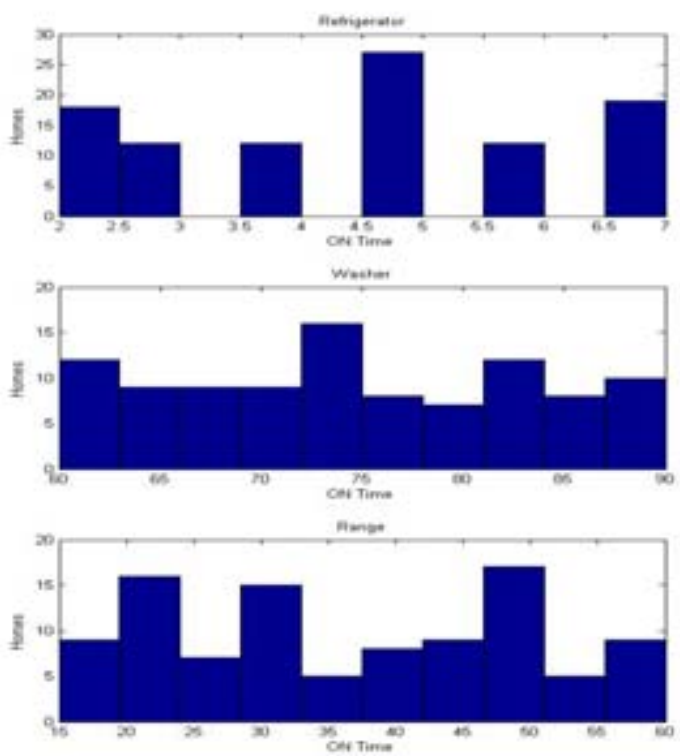
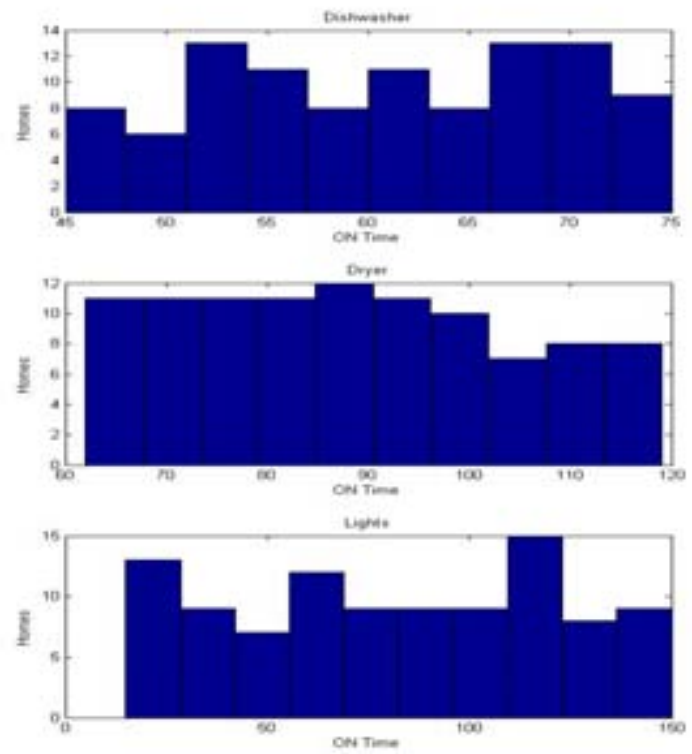

Figure 13. Appliance runtime (in minutes) for a community of 100 homes 


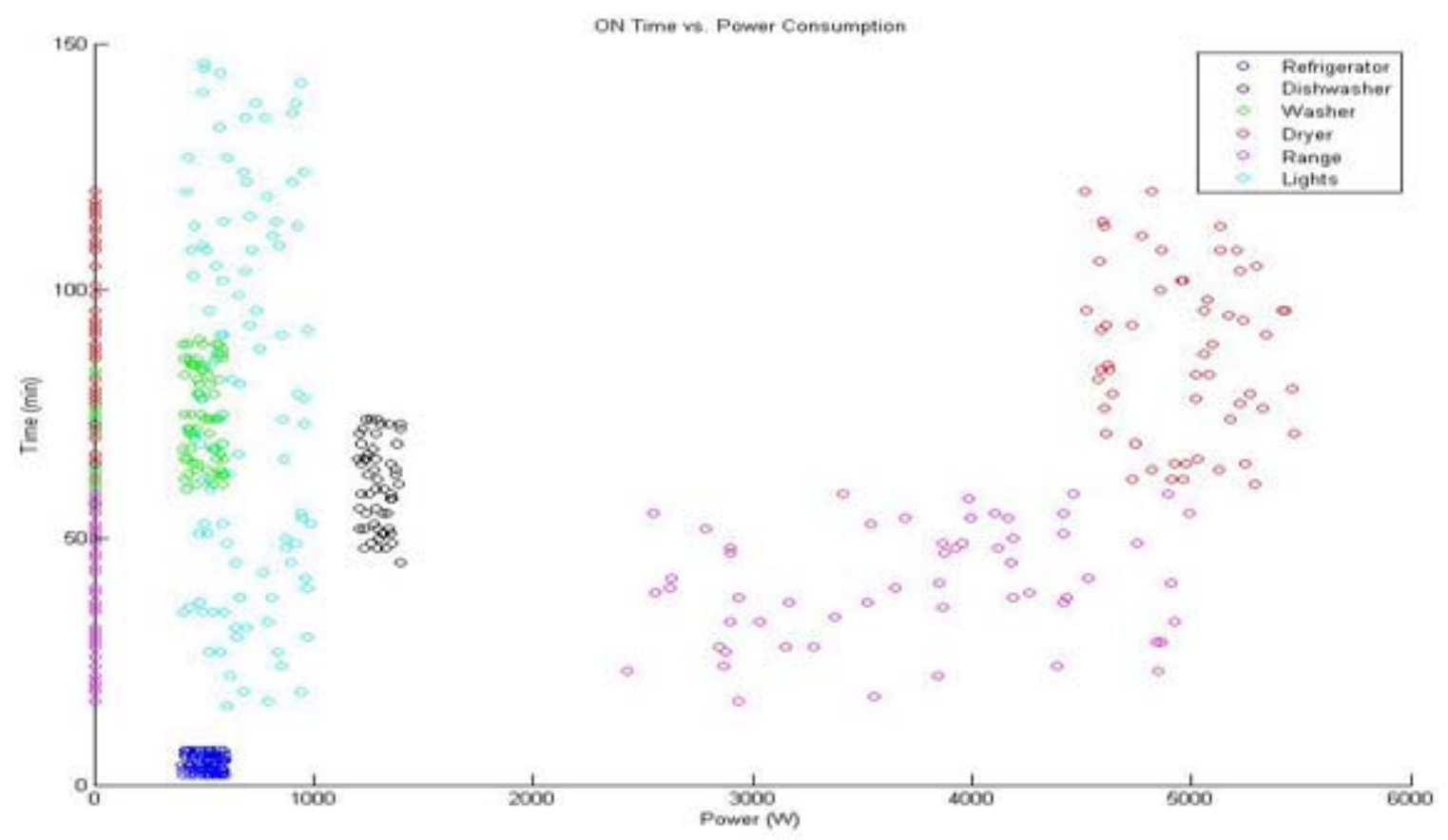

Figure 14. Appliance power and runtime for a community of 100 homes

\subsubsection{Generate Appliance Usage for One Week}

Accurately scheduling the residential loads within a community is a critical next step. This proves to be a challenging task and requires us to make many assumptions in order to keep the complexity of this model relatively low.

The model uses a pre-populated spreadsheet as shown in Figure 15. Each row represents a 15-minute interval, while columns represent appliances and lighting. The array of zeros and ones represent whether an appliance is turned on or off. There is one master spreadsheet for the entire community, and two individual day profiles - a weekday and a weekend profile. Holidays are assumed to be most similar to weekend days, and are therefore overwritten with weekend day profiles.

These spreadsheets were populated using LBNL graphs ${ }^{19}$ as a reference for peak appliance demand throughout weekday and weekend days. The graphs were translated to ones and zeros within the spreadsheet. However, to avoid every dishwasher turning on at 10:00 AM, another factor, called start time variability (STV), was introduced to distribute the start time of the appliance around the 10:00 AM timestamp. Based on data from $\mathrm{LBNL}^{19}$, the spread of start times was uniformly or normally distributed about the ones in the spreadsheet. Furthermore, as can be seen in Figure 15, both the washer and the dryer are being operated twice on Sunday, but the spreadsheet may be misleading as to their actual times of operation. Table 1 shows that both the washer and the dryer have a STV of 840 minutes or 14 hours, and their appliance demand distribution, Figure 16, shows a relatively uniform probability of dryer operation from $8 \mathrm{AM}$ to $10 \mathrm{PM}$ for a typical weekday in February. This simulates a little more normal behavior on the weekend but 
still has a mostly uniform distribution. Hence this MATLAB model will uniformly distribute the operation of the washer and dryer over this timeframe. However, the operation of a range has a more normal distribution in the morning and evening hours on the weekend and weekdays respectively, as seen in Figure 16. Therefore, the algorithm will normally distribute the range operation in the community between about $8 \mathrm{AM}$ Sunday morning and at 6 PM Sunday evening.

One of the shortcomings of this model is that it does not account for the chronological order of events; it may start a dryer before a washer. However, in a large community these events would represent a very small percentage of all events. Furthermore, as the model runs throughout the year, holidays are accounted for by exchanging week profiles, as seen in Figure 11, and accommodating holidays to the appropriate day of the week by substituting a weekend profile for a weekday holiday.

\begin{tabular}{|c|c|c|c|c|c|c|}
\hline & Refrigerator & Dishwasher & Washer & Dryer & Range & Lights \\
\hline 6:00 AM & 1 & 0 & 0 & 0 & 0 & 1 \\
6:15 AM & 0 & 0 & 0 & 0 & 0 & 0 \\
\cline { 2 - 7 } 6:30 AM & 1 & 0 & 0 & 0 & 0 & 0 \\
6:45 AM & 0 & 0 & 0 & 0 & 0 & 0 \\
\cline { 2 - 7 } 7:00 AM & 1 & 0 & 0 & 0 & 0 & 0 \\
7:15 AM & 0 & 0 & 0 & 0 & 0 & 0 \\
\cline { 2 - 7 } 7:30 AM & 1 & 0 & 0 & 0 & 0 & 0 \\
7:45 AM & 0 & 0 & 0 & 0 & 0 & 1 \\
8:00 AM & 1 & 0 & 0 & 0 & 1 & 0 \\
8:15 AM & 0 & 0 & 0 & 0 & 0 & 0 \\
8:30 AM & 1 & 0 & 0 & 0 & 0 & 0 \\
8:45 AM & 1 & 0 & 0 & 0 & 0 & 0 \\
9:00 AM & 1 & 0 & 1 & 0 & 0 & 0 \\
9:15 AM & 1 & 0 & 1 & 0 & 0 & 0 \\
9:30 AM & 1 & 0 & 0 & 0 & 0 & 0 \\
9:45 AM & 0 & 0 & 0 & 1 & 0 & 0 \\
10:00 AM & 1 & 1 & 0 & 1 & 0 & 0 \\
10:15 AM & 0 & 0 & 0 & 0 & 0 & 0 \\
10:30 AM & 1 & 0 & 0 & 0 & 0 & 0 \\
\cline { 2 - 7 }
\end{tabular}

Figure 15. Appliance scheduling spreadsheet

The implementation of the table in Figure 15 is highly subjective and may change radically from one community to another. Appliance usage patterns drift slightly as suggested by LBNL data, ${ }^{19}$ but to minimize model complexity these relatively minor drifts were ignored. Adding the LBNL data ${ }^{19}$ into this model should be improved by implementing the actual equations that produced the figures shown in Figure 16. Using piecewise continuous equations could more accurately distribute the use of appliances throughout a day without confining them to uniform or normal distributions. In addition, the existence of an appliance in the home does not necessarily imply its use. The current model assumes that all appliances existing in the community are used when the model encounters a " 1 " in the appliance scheduling sheet; this is probably not the case in an actual community. Data available at the EIA ${ }^{20}$ correspond to regionally dependent appliance usage patterns ${ }^{21}$. Further implementation of these studies would complement LBNL-provided data, thus increasing model accuracy. 

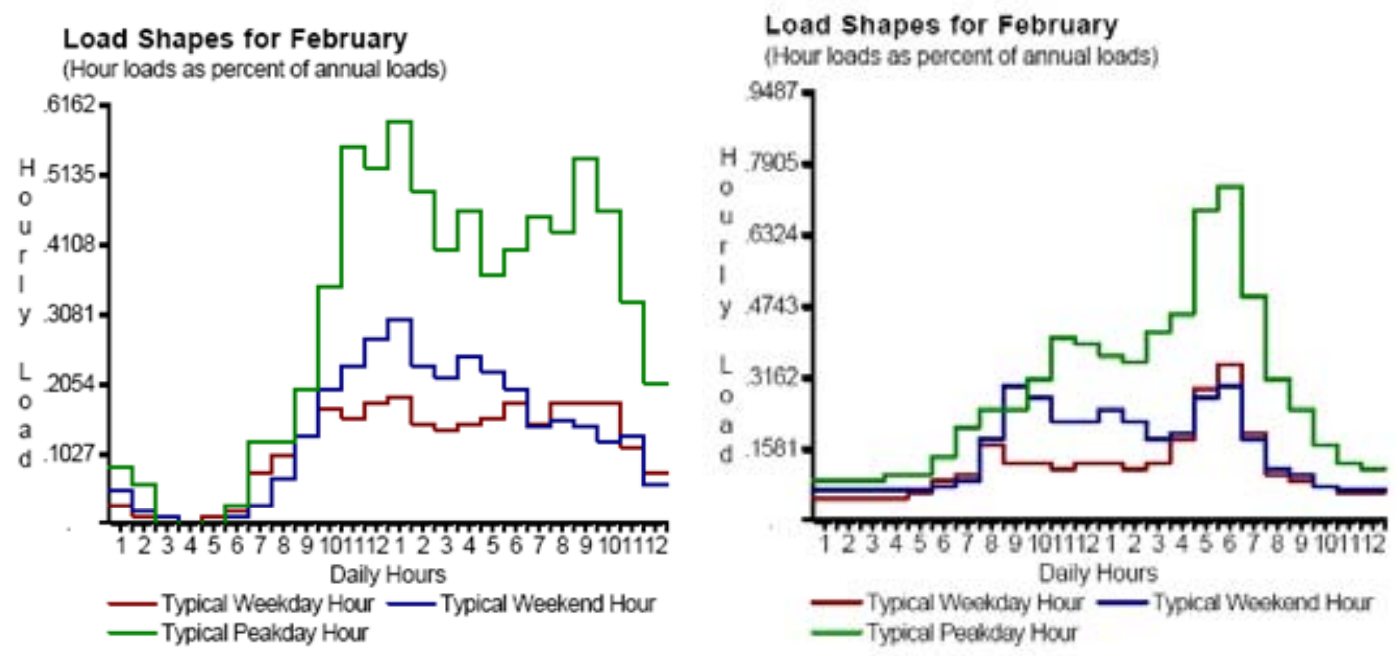

Figure 16. LBNL-provided chart ${ }^{19}$ corresponding to residential drying (left) and residential cooking (right)

The following section will address the interpretation of the simulation results.

\subsubsection{Modeling Results}

Once the simulation has generated a year's worth of data, interpreting and using these data is an important part of the validation exercise. One effect observed in reality is this notion of coincidence. Some utility customers could transiently demand upwards of 15$20 \mathrm{~kW}$ at any point in time, but the likelihood that every other home in the community demands a similar magnitude of power is statistically improbable. This concept is well understood when it comes to transformer sizing for a finite size community. ${ }^{22}$

We would expect the virtual community to exhibit a similar behavior. Figure 17 represents the power drawn by a community of 100 homes on a per-home basis, that is to say, that all individual home loads have been added together and divided by the number of homes in the community. The result is an average home consumption for that community. This averaging effect, as can be seen in Figure 17, results in an average home power profile that is smooth and continuous throughout the day. However, given the bottoms-up approach of our model, we are able inspect home load profiles individually and notice higher power demand peaks as individual loads are turned on and off within the home. Figure 18 illustrates a single home where peak demand reaches approximately $12.5 \mathrm{~kW}$ for a few minutes. It is important to note that this peak is constituted only of domestic appliances; it does not include HVAC loads. The reader may notice that Figure 17 does not seem to be representing any load corresponding to a clothes washer. Therefore, in Table 2, the total $\mathrm{kWh}$ consumed per appliance during the 24-hour period is displayed, and shows that, in fact, the washer does contribute, but in a small way, and the reasons for this behavior are explained. 


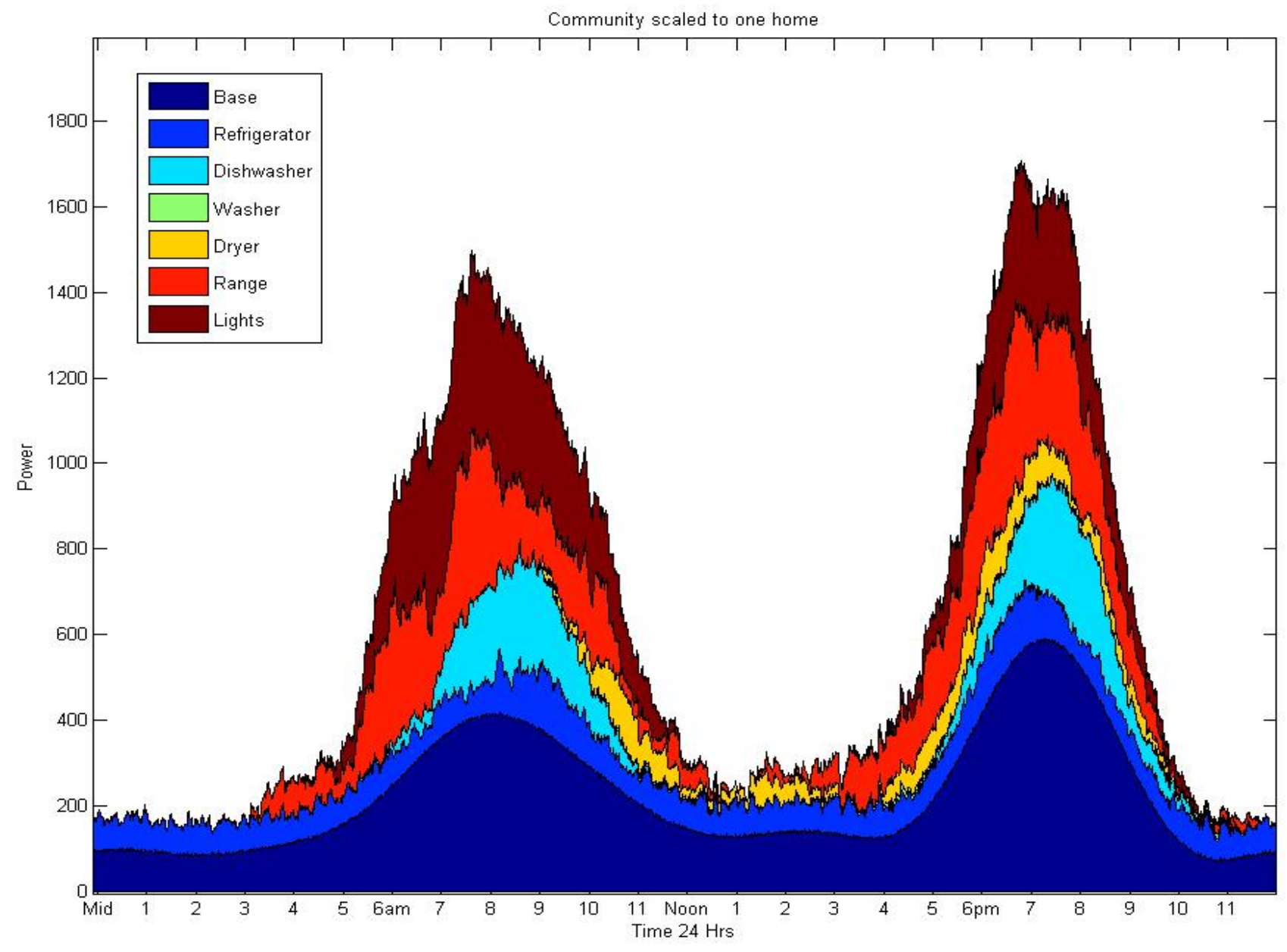

Figure 17. Power consumption by appliance (excluding HVAC) for a community of 100 homes scaled to 1 home 


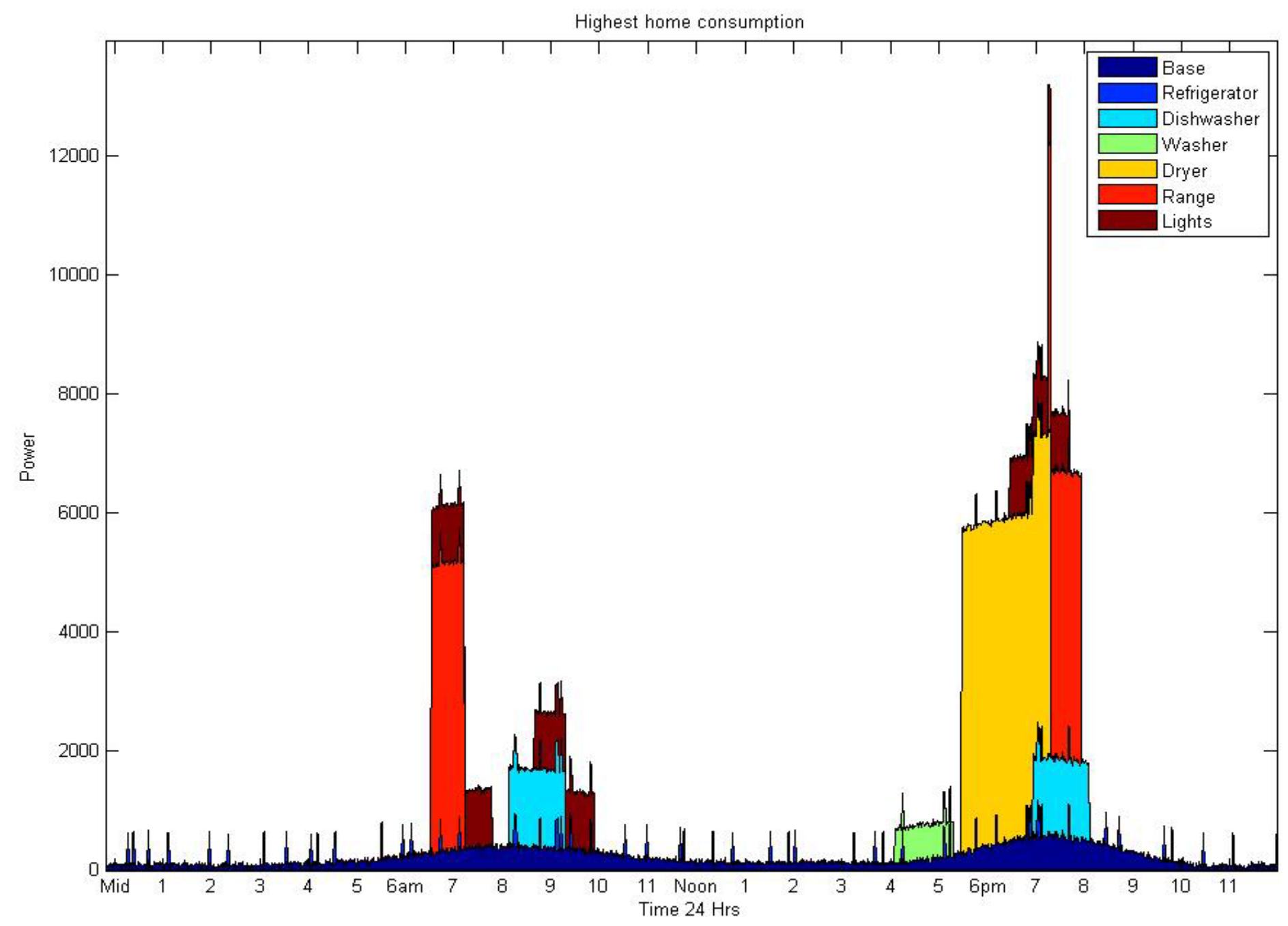

Figure 18. Power consumption per appliance (excluding HVAC) for a single home over a 24hour period 
Table 2. kWh Consumption per Appliance Represented in Figure 17

\begin{tabular}{|l|l|l|l|l|l|l|l|}
\hline \multicolumn{7}{|c|}{ One Day of Consumption per Appliance } \\
\hline Appliance & Base & Refrigerator & Dishwasher & Washer & Dryer & Range & Lights \\
& & & & & & & \\
\hline kWh/day & 1.138 & 1.859 & 1.547 & 0.068 & 0.677 & 2.682 & 4.306 \\
\hline
\end{tabular}

The first item to point out in Table 2 is that indeed the washer contributes $0.068 \mathrm{kWh}$ to the overall profile in Figure 17. The main reason this value is so low is that the average home power consumption profile, as illustrated in Figure 17, represents a clothes washer usage averaged out over a community where only a fraction of the homes have that appliance; this appliance penetration factor was discussed in section 3.4.1 and more specifically in Table 1. Therefore, averaging the use of the clothes washer over the entire community lowers the average due to the homes that do not own a clothes washer, hence making it difficult to see in Figure 17. Instead, if the $\mathrm{kWh}$ consumption for the clothes washer in Figure 18 (a profile for an individual home with a clothes washer) were calculated, the result would be $0.85 \mathrm{kWh}$ for that day, which, if projected over a year, yields approximately $200 \mathrm{kWh}$ annually. This value is within the Energy Star annual $\mathrm{kWh}$ consumption range for clothes washers ${ }^{23}$ of approximately $100 \mathrm{kWh}$ to $400 \mathrm{kWh}$. Furthermore, it is apparent that the dryer has a ten-fold impact over the washer as shown in Table 1. This is not completely unexpected since a washer usually consists of a drum or agitator motor, a water pump and in some models, a heating element, and only the motor operates during most of the cycle. On the other hand, a clothes dryer consists of a drum motor, a blower to circulate air and a substantial heating element, all operating simultaneously.

Another important point to remember is that the day profile shown in Figure 17 cannot simply be repeated 365 times to represent a year's worth of appliance power consumption. This is because weekends and holidays are simulated with different user behaviors while the model also varies statistically on a daily basis.

\subsubsection{Heating and Cooling Load Modeling}

In this part of the study we adopted a dynamic building energy simulation program (DOE-2.2). This program was developed by LBNL as a tool for HVAC load simulation to determine the adequate size of heating and/or cooling systems. The program is able to simulate energy performance and HVAC loads of a building hour by hour for each of the 8760 hours in a year. The DOE-2.2 program is composed of four modules that are executed sequentially. The LOADS module calculates the hourly cooling and heating loads using algorithms suggested by the American Society of Heating, Refrigerating, and Air-Conditioning Engineers (ASHRAE). The SYSTEMS module simulates the performance of secondary HVAC equipment under conditions of maintaining indoor comfort within the building. The PLANT module simulates the energy performance of primary HVAC equipment, such as chiller, boiler, and cooling tower, on the basis of operating conditions and part load performance characteristics. The maximum chiller capacity can be acquired from the PLANT module. The fourth module, ECONOMICS, tackles economical benefit analysis, and was not included in the current study. 
eQUEST is a graphical front end to the widely used freeware building energy analysis program DOE-2 (version 2.2). DOE-2 is a powerful building simulation program written in Fortran. However, setting up a building simulation using the DOE-2 engine is quite complicated. The user is required to provide a text file containing all building parameters such as geometry, construction materials, weather data, etc., in DOE-2's building description language (BDL). This is very cumbersome for reasonable sized buildings. eQUEST provides a layer of graphics and wizards on top of DOE-2 and contains a parser to convert the graphical inputs into BDL that can then be processed by DOE-2. For example, eQUEST allows the user to draw the building footprint shape using a sequence of keyboard and mouse commands rather than specifying each vertex in a text file. In addition, it contains features such as the ability to import building plans directly in as AutoCAD files. Another feature is that the building model can be specified via wizards, which are pre-populated with sensible default values for unknown building parameters. In addition, there is a detailed data edit mode, which exposes most of the functionality of DOE-2 while still retaining a user-friendly graphical interface.

A standard four-bedroom $2500-\mathrm{ft}^{2}$ colonial-style home was chosen for the simulation. Since the size of the PV array was chosen to achieve a specific PV penetration (in nameplate array size divided by the maximum 15 minute average total load), the size of the home does not impact the quantification of enhanced reliability due to the presence of PV (in \% penetration). Also, without details of the potential market for enhanced reliability with batteries, $\mathrm{PV}$, and load management, it is difficult to posit the size of the average home in such a community. The layout from a builder's Web site in the northeastern United States is used for this purpose. The DOE-2.2 uses meteorological data to acquire accurate and local climatically responsive HVAC loads. NREL's Resource Analysis group provided data for three locations: California, Colorado, and New Jersey. The HVAC meteorological simulation used data containing 15-minute weather information of outdoor dry and wet bulb temperatures, relative humidity, total horizontal solar radiation, normal solar radiation, and wind-speed for the whole year.

The other key data that were assumed are occupancy levels, HVAC set points, and lighting profiles (used only to calculate the heat gains). Many existing literature sources were consulted to obtain this data. Sample results for a whole year of simulation are shown in the figure below. The results are validated by the EIA Web site. 


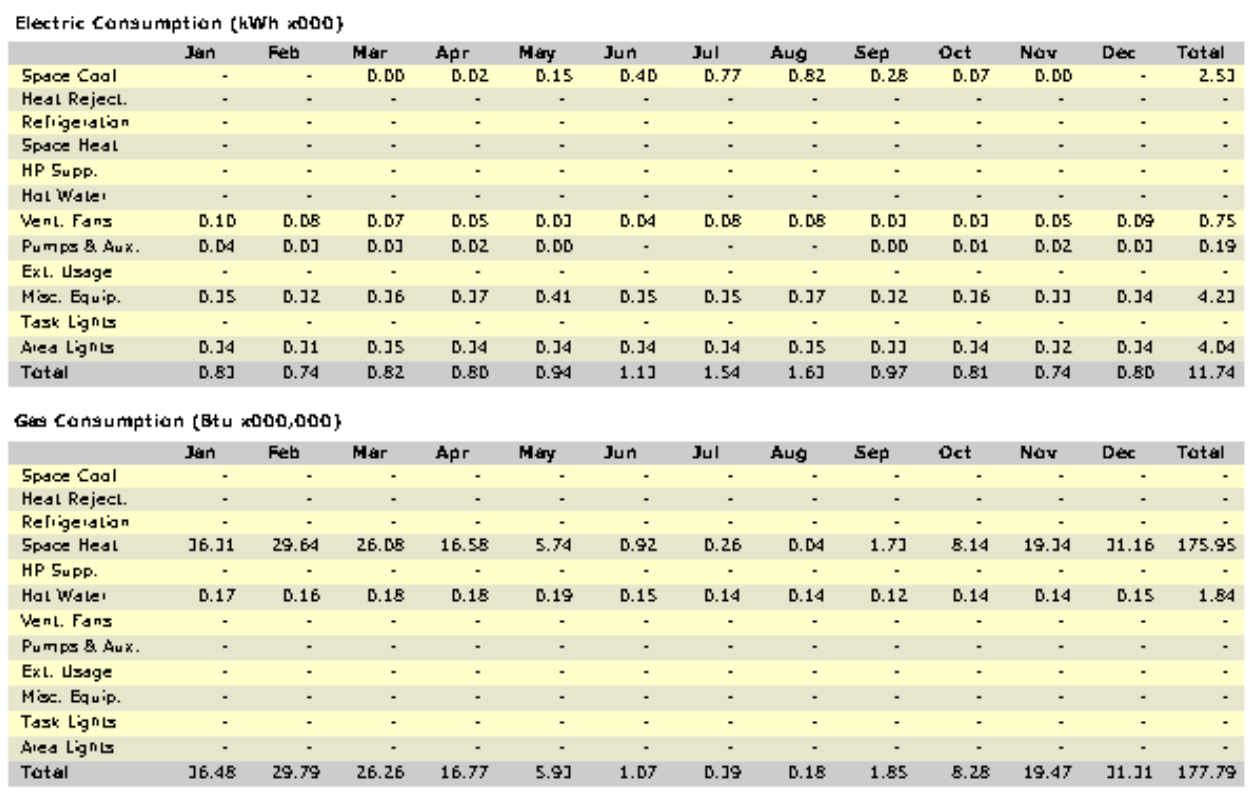

Figure 19. Detailed electric and natural gas consumption over a year

During outages, we assumed that the homeowners would be able to relax the constraints on the heating and cooling set points. A new table of set-points was generated with this relaxed constraint and the DOE2.2 simulations were repeated to get a new load profile, which was used for reliability calculations during outage conditions. A plot of regular (non-outage conditions) and critical loads for one whole year in Colorado is shown in Figure 20.

Heating/Cooling Load for the Whole Year

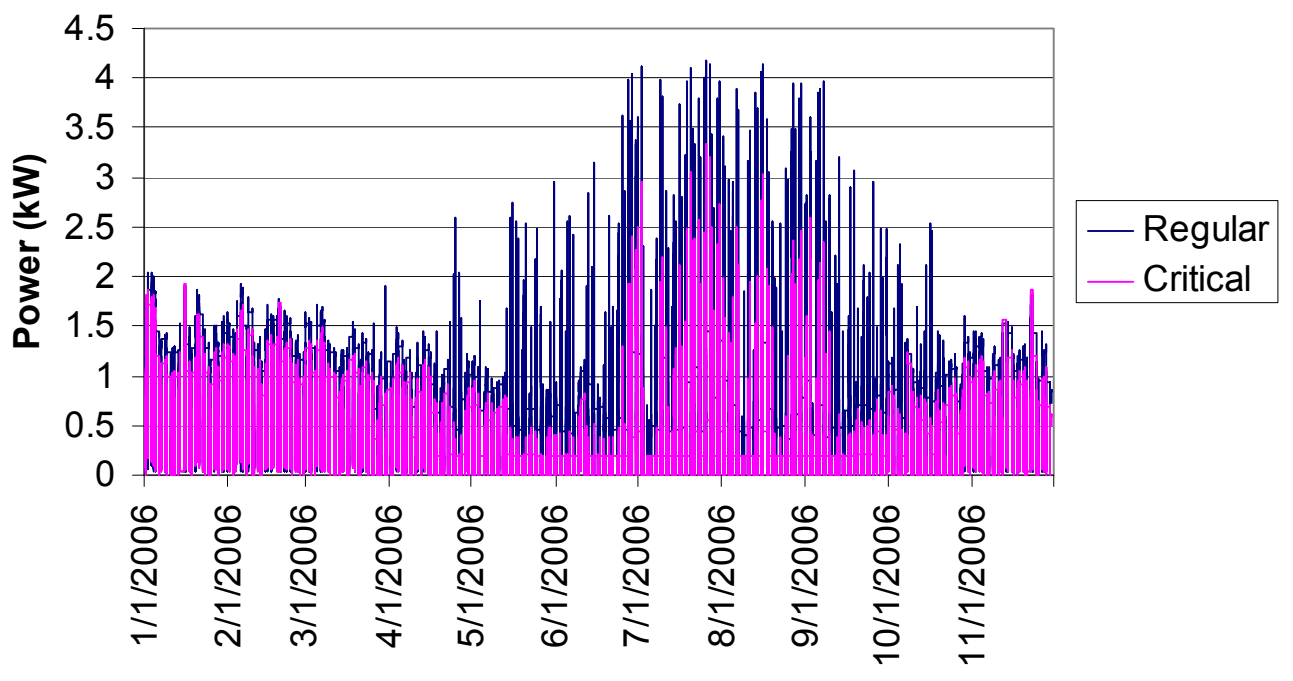

Time

Figure 20. HVAC power consumption of a Colorado home over one year 
Furthermore, to account for different types of heating and cooling topologies, we repeated the DOE2.2 model, and the results were then weighted and combined to provide average power consumption for the region. Two methods for heating and cooling were considered. The first uses direct expansion cooling and a gas furnace, and the second method uses a heat pump for both heating and cooling needs. Data gathered for the Northeast shows a $66 \%$ use of direct expansion cooling with a gas furnace and $33 \%$ use of a heat pump; this ratio was assumed to be constant for the other two regions. Since the DOE2.2 model represents energy consumption for one home, the simulation was repeated twice for each region, once with each method. The results were then weighted and combined to generate an average home consumption for that particular region.

\subsection{Energy Modeling}

In order to determine the enhanced reliability associated with PV and energy storage, an energy balance model was developed. This model incorporates outage duration, timing, and the number of customers affected (based on the reliability statistics described earlier), and simulates PV output and battery output during an interruption for an individual home. Another key input to the model is the load profile (unique for each region and community size). Developing a model capable of simulating the critical and total load profiles, in 15minute intervals, comprised a substantial component of the effort in this study.

The modeling approach is described below:

1. Loads for a community of size $\boldsymbol{n}$, in geographic location $\boldsymbol{m}$, have been classified as critical or non-critical for each 15-minute period of the day, for 365 consecutive days.

2. The incident solar insolation and temperature is provided for location $\boldsymbol{m}$.

3. The PV output is calculated for location $\boldsymbol{m}$.

4. If there is no interruption, electricity is consumed from the PV array and the grid charges the battery

5. If the battery is charged, $\mathrm{PV}$ is used to reduce grid consumption

6. If there is an interruption, non-critical loads are shed and available PV energy is used to meet critical loads

7. The battery is discharged to meet the remaining critical loads

8. When battery is completely discharged, critical loads are shed and an interruption occurs.

9. After the interruption, the grid meets all loads. Restart at Step 2.

This approach is highlighted in Figure 21. 

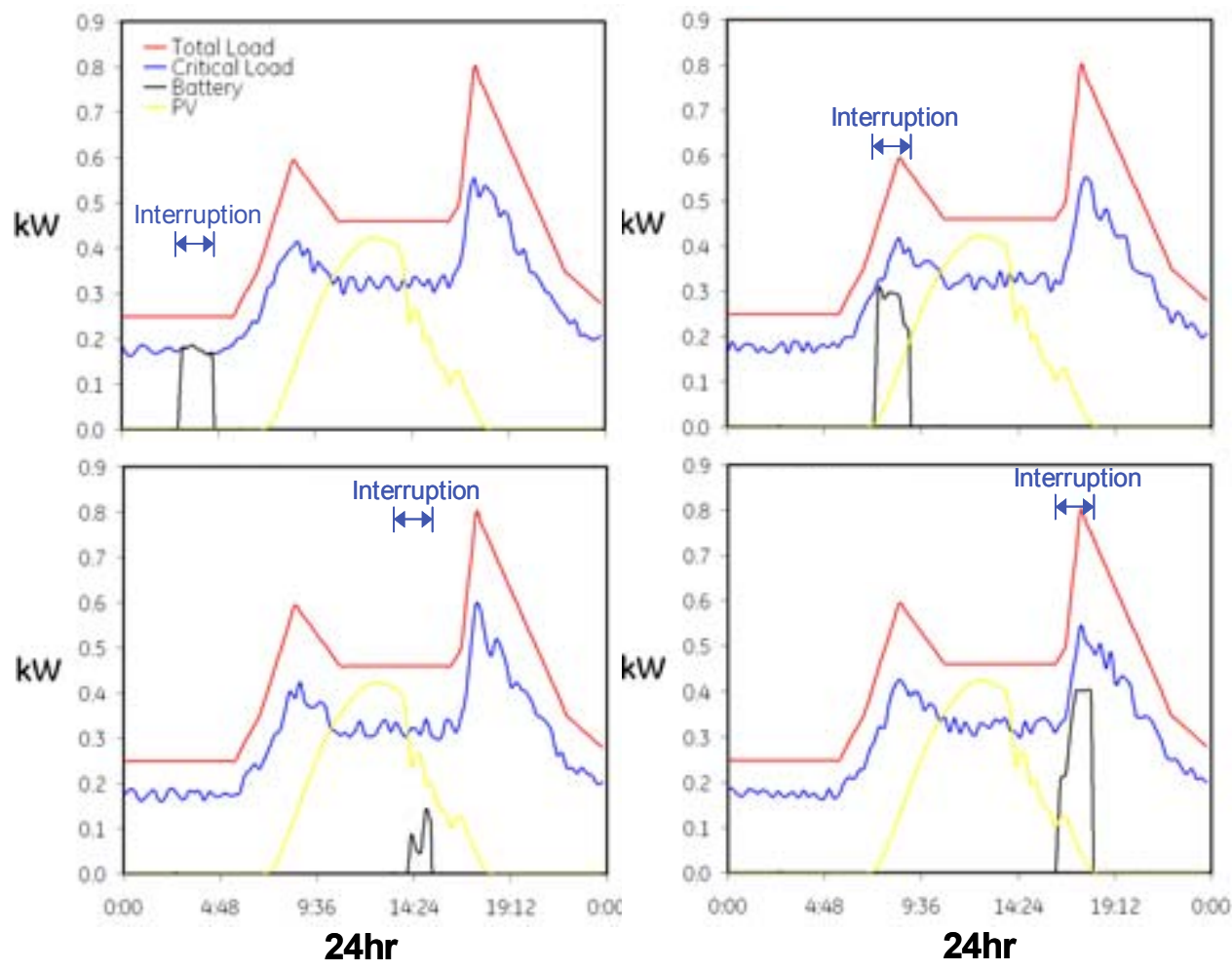

Figure 21. Energy modeling simulation validation

Figure 21 shows an interruption occurring at different times of the day. Based on the modeling approach described above, energy from the battery and PV array was used to meet the critical loads for each home. The top left figure shows the battery meeting the entire critical load in the early morning hours (prior to sunrise). The top right figure shows the battery meeting the critical load prior to sunrise and meeting a portion of the critical load after the PV is available. The bottom left figure shows significant contribution from the PV array. The bottom right figure shows the battery discharging all of its energy prior to the end of the interruption. The customer would experience an interruption.

\subsubsection{Battery Energy Storage System}

Since the purpose of this study is to quantify the enhancement in reliability, a specific battery was not chosen in order to ensure technology neutrality. However, it was necessary to specify some battery parameters. The battery system was assumed to operate within a $10 \%$ to $90 \%$ depth of discharge (DOD) range for the maximum rated capacity in $\mathrm{kWh}$. In this analysis we assumed that the battery (and power electronics) has a $90 \%$ charging and discharging efficiency and appropriately sized power electronics to meet the maximum critical load the home will experience during the year. It should be noted that based on statistical outage data, a battery in an average home in the United States could expect to be used, on average, once or twice per year (see above discussion on reliability statistics). We assumed that the energy storage system was located at each home in the community and represents a stand-alone battery or perhaps, in the future, the battery of a plug-in hybrid electric vehicle. For the purposes of this analysis, the relatively high 
efficiency may slightly overstate the impact of the battery on enhancing reliability. For details about battery specifications, see Wiegman \& Lorenz ${ }^{24}$ and Stevens \& Corey ${ }^{25}$.

\subsubsection{Photovoltaics}

The global insolation data were provided for three locations in the United States (Golden, Colo., Hanford, Calif., and Sterling, Va.) for the year 2003. The global insolation was translated into the actual insolation incident on the PV array. The incident insolation was then used to determine the maximum electrical power that the PV array can deliver. The following equation was used to model the PV output for a south-facing array, based on a PV array developed using the GE 200-W module. The equation was derived from Messenger \& Ventre ${ }^{26}$.

$$
P_{\text {array }}=\left(-0.006825 T_{\text {ambient }}+1.171\right) P_{\text {incl }} P_{f c} \frac{P_{\text {global }}}{P_{\text {isoref }}} P_{\text {maxref }}
$$

where,

$P_{\text {global }}$ is the global solar insolation $\left(\mathrm{W} / \mathrm{m}^{2}\right)$ data, provided by NREL, for the three regions described above. The data varies from zero to the maximum daily solar insolation (in 15-minute intervals for an entire year).

$P_{\text {incl }}$ is an inclination correction that varies, during the daylight hours, between zero and unity, to account for the orientation of a south-facing array with respect to ground level.

$P_{f c}$ is a longitudinal correction that varies, during the daylight hours, between zero and unity, to account for the location of the site on the earth, and within the time zone. There are corrections for daylight savings time.

$P_{\text {maxref }}$ is the maximum output power of the PV array at $1,000 \mathrm{~W} / \mathrm{m}^{2}$ and $25^{\circ} \mathrm{C}$.

$P_{i s o r e f}$ is the reference solar insolation $\left(1000 \mathrm{~W} / \mathrm{m}^{2}\right)$.

$T_{\text {ambient }}$ is air temperature near the $\mathrm{PV}$ array $\left({ }^{\circ} \mathrm{C}\right)$.

The parameters related to the array performance were obtained from the specifications of a GE 200-W solar array ${ }^{27}$ that was fitted to the Shockley Solar cell equation model and scaled using the electrical output power for a particular site. The Shockley model was used to determine the maximum electrical power of the PV array as a function of insolation level and normalized to the power level data given for a site. Since this model is complex, a linear fit equation was derived. This fitted equation introduces minimal error to the results as shown in Figure 22. 


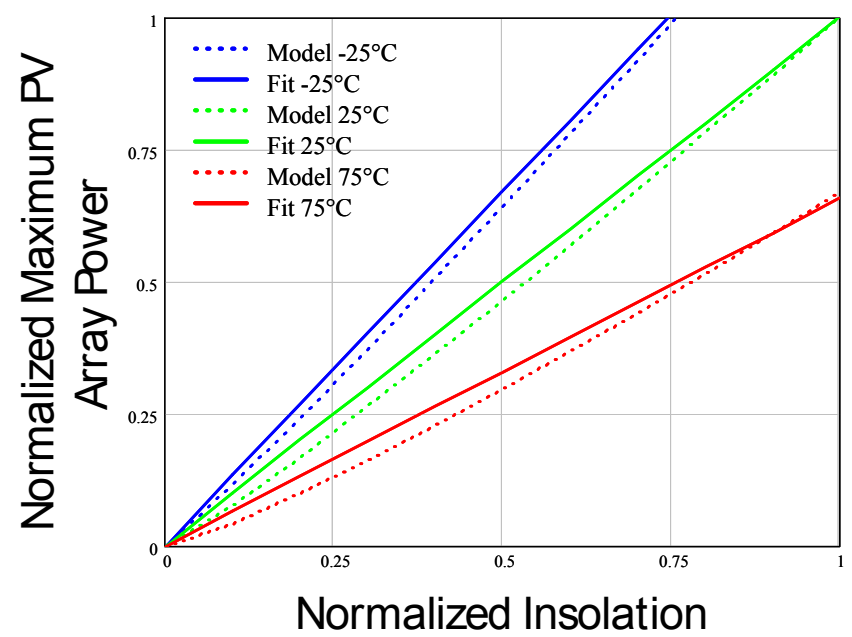

Figure 22. Normalized PV model equation fit

The following assumptions were made:

- The temperature of the PV array is uniform over the entire array.

- The wind and ambient temperature effects on PV array were neglected.

- The effect of albedo was neglected.

- PV inverter efficiency was assumed to be $95 \% \mathrm{CEC}$ and constant over the entire operating range of inverter operation.

- The insolation is uniform across the entire PV array.

- Effects of shading are neglected.

- The PV array is south-facing only.

- The PV array design was electrical-power driven and not based on a specific PV array design of $x$ modules in series.

The equation used to model the PV output incorporated information and equations from multiple sources $\left[{ }^{28},{ }^{29}\right]$.

Hourly PV output (kW AC) from a 1-kW south-facing array with a $25^{\circ}$ tilt located in Golden, Colorado, was obtained from NREL based on simulations using PVWatts, a performance calculator for grid-connected PV systems. The insolation data were obtained from the NREL SPRL site in Golden and the weather data were taken from a nearby airport. The PVWatts output data were compared with the model results for five GE 200$\mathrm{W}$ arrays with the same orientation. As shown in Figure 23, the hourly PV output from the model compares extremely well with the NREL data from 2003 during the middle part of the year. However, during the beginning and the end of the year the discrepancy between the model's output and the NREL data is observable. As shown in the bottom right of Figure 23, the cumulative error increases during the beginning and end of the year, but remains nearly constant during the middle part of the year. The difference 
between the annual kWh produced by the model and observed output from the $1-\mathrm{kW}$ array in Colorado is $14 \%$. This was deemed to be adequate for quantifying the enhancement in reliability within a distribution feeder. The model was deemed valid for a study focused on the impact of PV, energy storage, and load control on enhanced reliability in a distribution feeder.
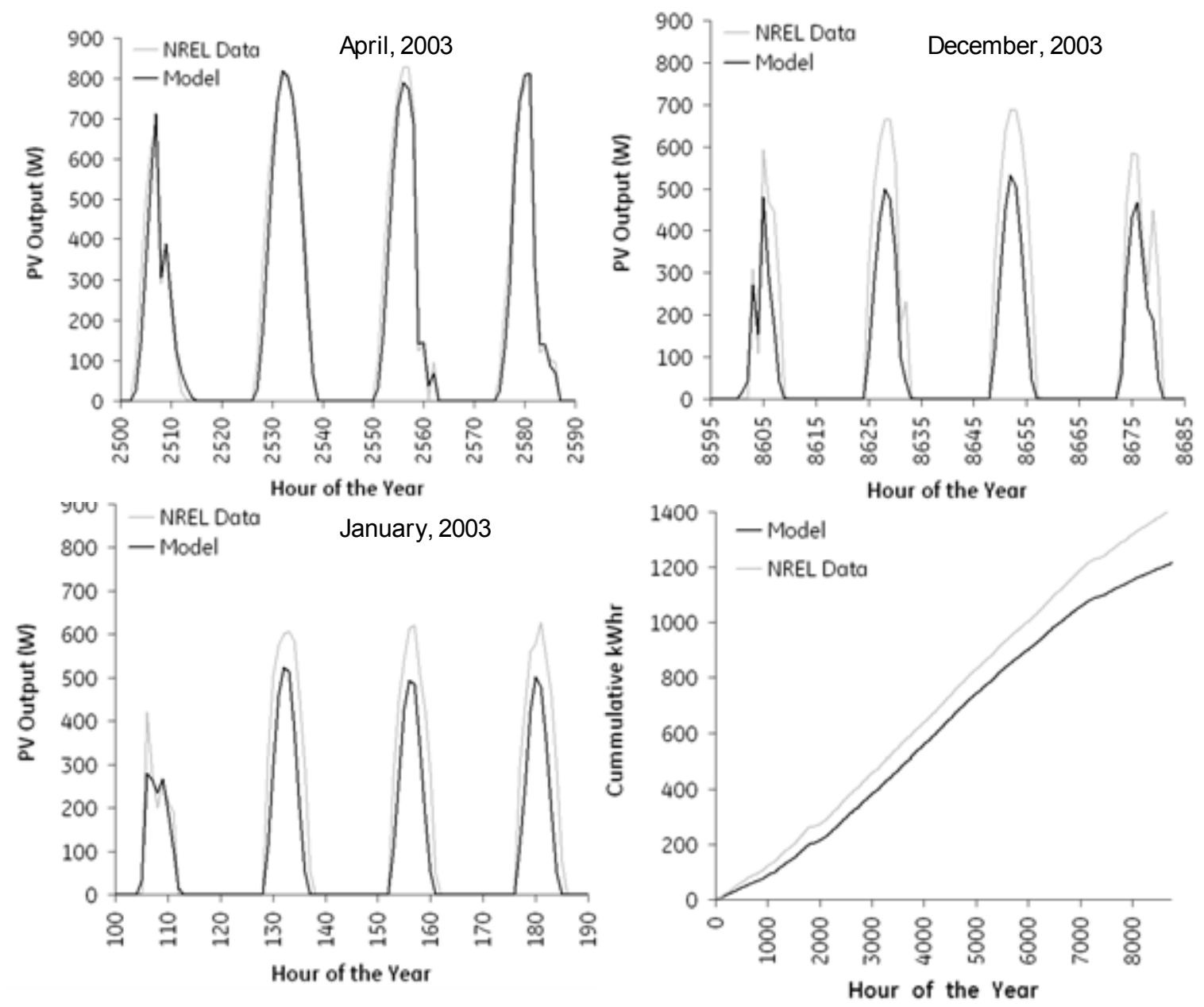

Figure 23. Model validation for Golden, Colo. Data obtained from NREL. 


\section{Project Results}

A design of experiments was conducted in order to identify the parameters of interest (Table 3). These parameters were combined as inputs to the model.

Table 3. Design of Experiments for Reliability Enhancement Modeling

\begin{tabular}{|c|c|c|}
\hline Community Size & $10,100,1000$ homes & $\begin{array}{l}\text { More homes translate into more load } \\
\text { profile smoothing. }\end{array}$ \\
\hline Geographic Region & $\begin{array}{l}\text { Sterling, VA, Hanford, } \\
\text { CA, Golden, CO }\end{array}$ & $\begin{array}{l}\text { Insolation and temperature data were } \\
\text { used for PV modeling and load modeling } \\
\text { in three regions of the United States. }\end{array}$ \\
\hline $\begin{array}{l}\text { Energy Storage } \\
\text { Capacity }\end{array}$ & $0,0.5,1.0,2.0,5.0 \mathrm{kWh}$ & $\begin{array}{l}\text { Various battery sizes were chosen to } \\
\text { augment the enhancement in reliability } \\
\text { provided by solar power }\end{array}$ \\
\hline $\begin{array}{l}\text { Photovoltaics } \\
\text { Penetration }\end{array}$ & $\begin{array}{l}0,5,10,30,50 \% \text { total } \\
\text { maximum peak } 15 \mathrm{~min} \\
\text { load. }\end{array}$ & $\begin{array}{l}\text { Various penetrations of PV energy were } \\
\text { chosen to enhance the reliability in a } \\
\text { distribution feeder. }\end{array}$ \\
\hline
\end{tabular}

The community size, geographic region, PV array size (chosen to meet specific PV penetration levels), and battery capacity were taken as input parameters to the model (see Table 4). The output table is also shown in Table 2. For the simulation presented here, the outage is 90 minutes in duration (six 15-minute intervals) and affected 872 customers. The outage started at the $7884^{\text {th }} 15$-minute time stamp of the year (March 24 at 2:45 PM). Based on the input parameters for this simulation, both the unserved critical $\mathrm{kWh}$ and the outage duration decreased due to the load support provided by the battery ( $1 \mathrm{kWh})$ and PV $(2.1 \mathrm{~kW})$.

Table 4. Model Input and Output Tables

\section{INPUT}

\section{OUTPUT}

Distributed Generation - Photovoltaics

\begin{tabular}{|lc|}
\hline Location & $\mathrm{CO}$ \\
Community Size & 100 \\
Photovoltaics & $2.1 \mathrm{~kW}$ \\
\hline PV Penetration & $\mathbf{5 0 . 0 \%}$ \\
\hline Energy Storage - Battery & \\
\hline Size of Battery & $1 \mathrm{kWh}$ \\
Round Trip Efficiency & $90.0 \%$ \\
Limits from Max/Min & $0.1 \mathrm{kWh}$ \\
\hline
\end{tabular}

Reliability Simulation

\begin{tabular}{|lcc|}
\hline Duration (15min intervals) & \multicolumn{2}{c|}{6} \\
Timing (15min interval) & \multicolumn{2}{c|}{7884} \\
No. Customers Affected & \multicolumn{2}{c|}{872} \\
\hline Performance & Before & After \\
Oritical kWh unserved & 1.011 & 0.339 \\
Outage Duration & 6 & 2 \\
\hline
\end{tabular}

The entire combinatorial space was considered in the study. The following cases are presented here: (1) The impact of community size and geographic region on customer reliability, and (2) The impact of PV penetration and battery storage capacity on customer reliability. 


\subsection{Community Size and Geographic Region}

In this study, PV penetration was defined as the ratio of the maximum solar array output per home (in a specific region of the country) to the maximum total load for the home in a given year (on a 15-minute interval basis). Based on this definition, the number of arrays on the roof a home was selected to achieve a specific PV penetration level. The number of panels on a roof varies depending on the region and the total load of the home. For example, an average home in California consumes less electricity than an average home in Colorado, so a smaller array on a home in California provides the same PV penetration level as a larger array on a home in Colorado. Such scaling is important to allow for consistent comparison between regions.

The range of PV penetration levels and energy storage capacities were chosen and simulated in the energy systems model based on the reliability statistics for utility A in 2005. The many combinations of PV penetration, battery size, community size and geographic region were taken as inputs to the model. The results of the study present the fraction of each reliability index as compared with the same simulation without the presence of PV, energy storage, or critical load controls. This was done to allow for a simple comparison of relative improvement in each reliability index for each simulation. To summarize, the following reliability indices were considered:

- Critical SAIDI - average duration of critical load interruptions.

- Critical SAIFI - average number of interruptions per customer.

- Unserved Critical Load (UCL) - annual unserved critical load (kWh) on a circuit.

The indices are based on common distribution reliability indices (IEEE 1366), but on a critical load basis. By using reliability indices familiar to the electric utility industry, the impact of PV, energy storage, and load controls on enhancing reliability can be quantified using metrics that are meaningful to a broader audience.

The results for three PV penetration levels $(10 \%, 30 \%$, and $50 \%)$ for each region and community size (without the presence of a battery) are presented in Figure 24. The PV penetration levels considered cover a wide range of PV output for a given home. The results reveal a definite trend in reliability enhancement as PV penetration levels increase. These results indicate that if the PV inverter can function during an outage, the presence of PV within a community will completely eliminate some outages (improve critical SAIFI) or allow consumers to reduce their outage duration (improve critical SAIDI).

The same simulation was performed with a $1-\mathrm{kWh}$ battery in each home within the community (see Figure 25). The battery provided a substantial reduction in outage duration and frequency, and largely overshadowed the improvement in reliability resulting from the increase in PV penetration levels. The relative impact of PV penetration, as compared battery size, on the overall reduction in critical SAIDI, critical SAIFI, and unserved critical $\mathrm{kWh}$ will be discussed in the next section. 

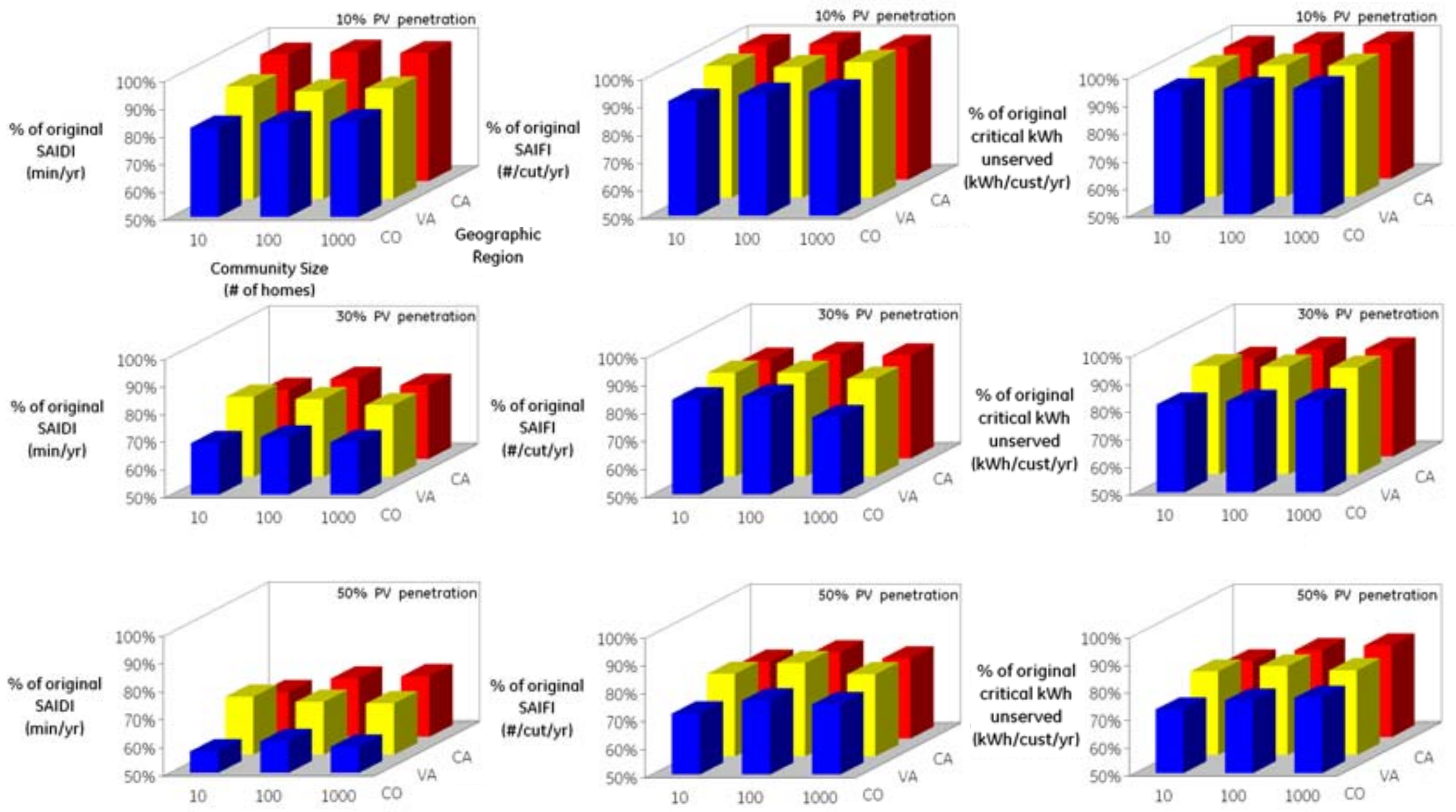

Figure 24. Customer reliability for $10 \%, 30 \%$, and $50 \%$ PV penetration, with no battery, for three community sizes in three regions of the United States. 

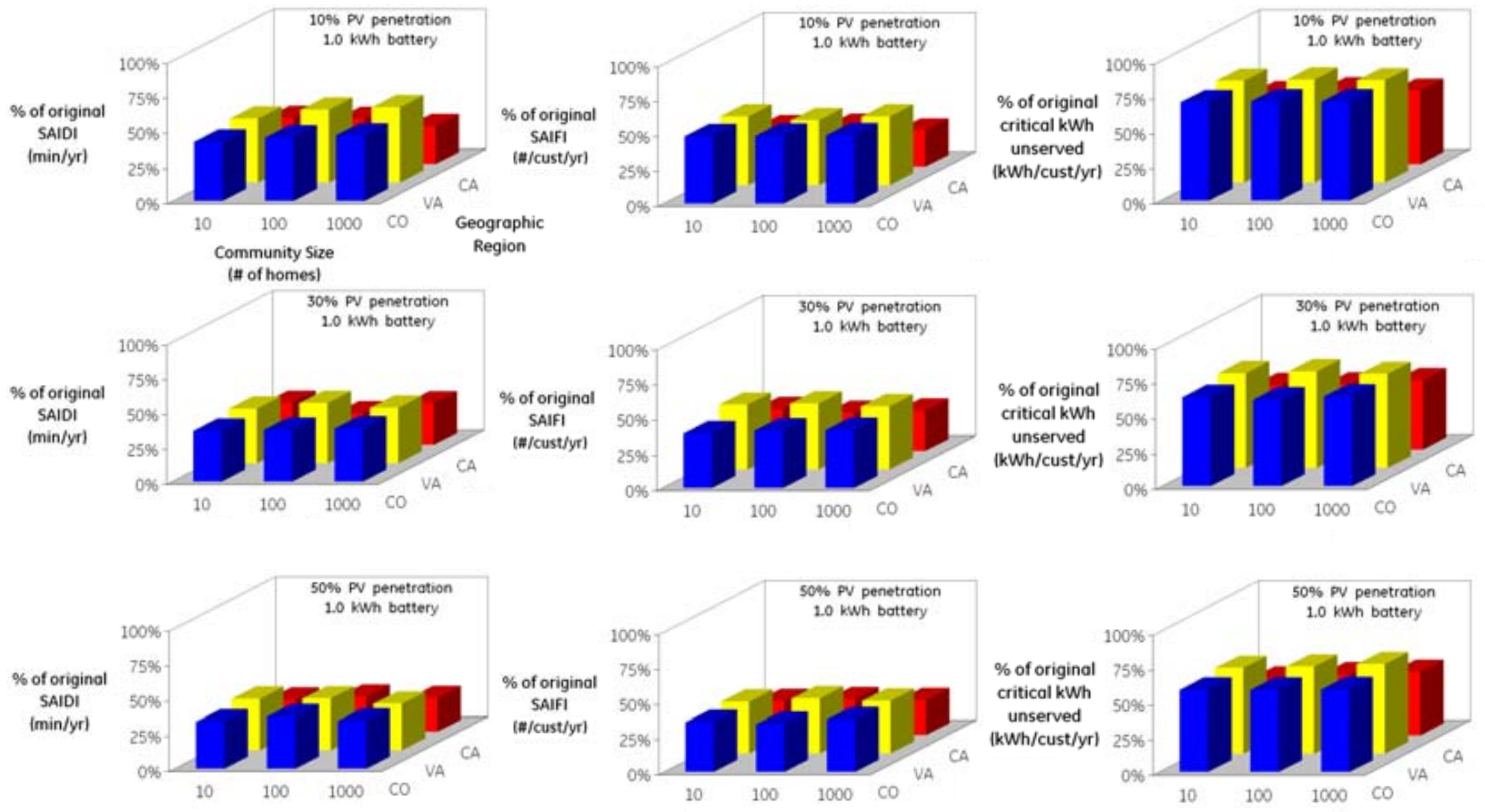

Figure 25. Customer reliability for $10 \%, 30 \%$ and $50 \%$ PV penetration, and a 1-kWh battery, for three community sizes in three regions of the United States. 
As we mentioned earlier, the community size was intended to represent the impact of coincidence factor (a smoother load profile represents a community that was able to distribute the load more evenly during an outage). A 1000-home community should provide a smoother load profile than a community consisting of 10 homes. We therefore expected that reliability indices would show improvement for larger communities. However, based on these results, there seems to be no common trend between reliability enhancement (reduction in the proposed reliability indices) and community size. Since the electric load modeling is broken into appliances and HVAC, and the methodology for accounting for community size varies between appliances and HVAC, it is difficult to postulate that the community size is truly a measure of energy management efficacy. For the HVAC simulation there is no randomness associated with the number of homes (e.g., the value for 100 homes is obtained by multiplying the HVAC load curve for a single home by 100). Conversely, for the appliance simulation, the number of homes affects the coincidence factor. Since the HVAC results are highly sensitive to some parameters, such as the thermostat settings in each region of the country, the results rely heavily on the assumptions for thermostat settings. Additional research could further refine assumptions. Therefore, residential load modeling is cited as a significant future research activity that will greatly enhance quantification of reliability enhancement.

In the case of geographic region, each region experiences an enhancement in reliability as the penetration of PV increases. For the simulation presented in Figure 24, the reliability enhancement in Colorado is generally more pronounced than the other two regions. Since the size of the PV array is chosen based on the maximum total load in a region, and Colorado has a smaller ratio of critical load to maximum total load than the other two regions, Colorado should experience a more significant enhancement in reliability than the other two regions because ample solar power is available to meet a lower critical load during an outage. Since the classification of loads as being critical or non-critical significantly affects the results for each region, additional research on residential load modeling would allow for a more definitive conclusion on how reliability enhancement varies from region to region. Fifteen-minute appliance and HVAC load data, as well as customer preferences regarding critical load classification, may reveal that a region may have a unique preference in classifying loads as critical and deferrable. Data on consumer preferences in each region will greatly enhance this analysis.

For the simulation with the 1-kWh battery, California experiences substantial reliability enhancement, even with $10 \%$ PV penetration. Since annual electricity consumption in California is lower than that of Virginia and Colorado, a 1-kWh battery has a more significant impact on reliability enhancement in California. The presence of a 1-kWh battery in each home contributes to reliability enhancement by more than the increases in PV penetration discussed above. This aligns with the commercial building back-up power market, where batteries are sometimes used to meet critical loads during an outage.

\subsection{Battery Size and PV Penetration}

If an energy storage medium, such as a battery, is also incorporated into a community, there is an opportunity to further enhance reliability. Early analyses revealed that the presence of a $10-\mathrm{kWh}$ battery would completely eliminate all outages. As a point of 
reference, a $10-\mathrm{kWh}$ battery is approximately the size of battery one can expect in future plug-in hybrid vehicles.

The enhancement in reliability is presented for a 100-home community in Golden Colo. (see Figure 26, Figure 27, and Figure 28). A range of battery sizes and PV penetration levels was considered.
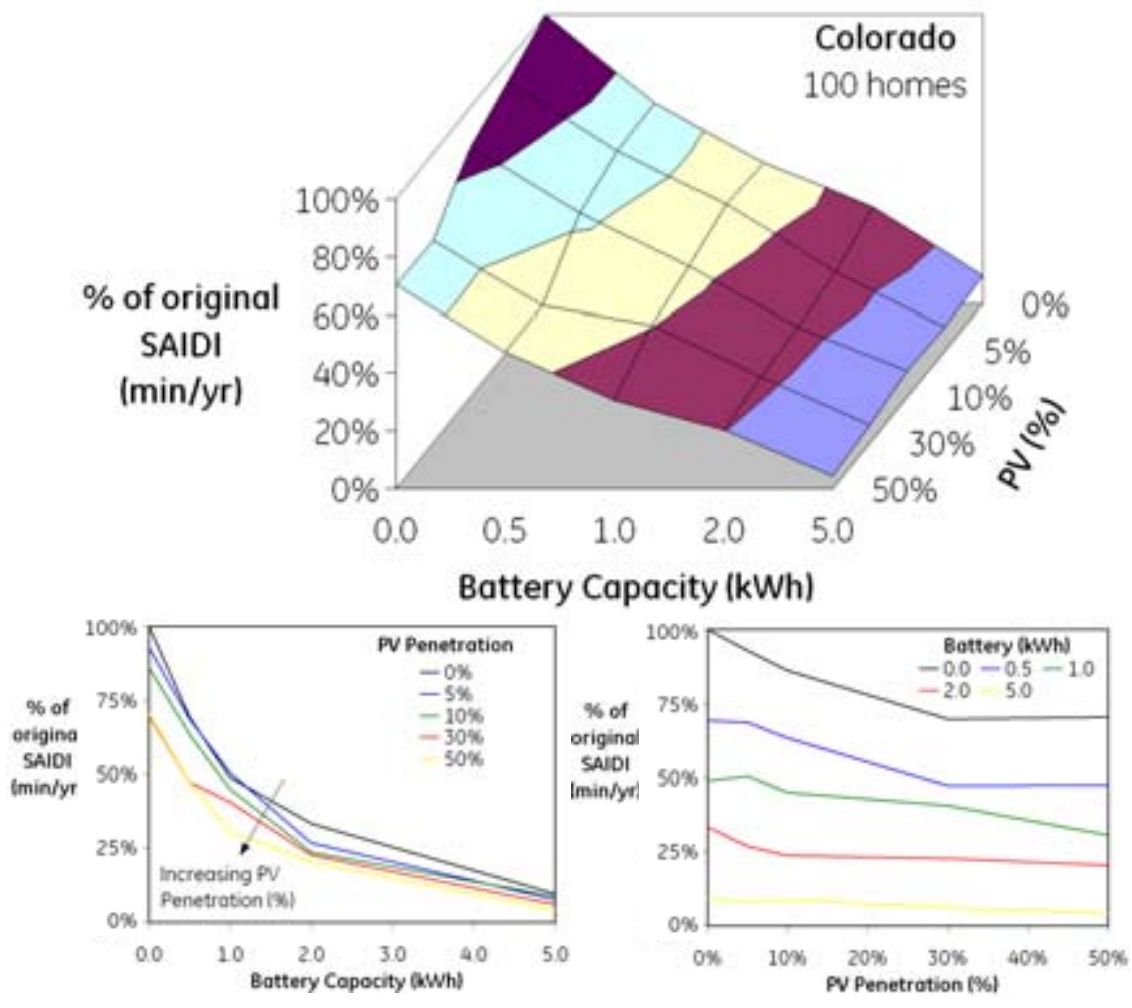

Figure 26. Critical SAIDI for a 100-home community in Golden, Colo. 

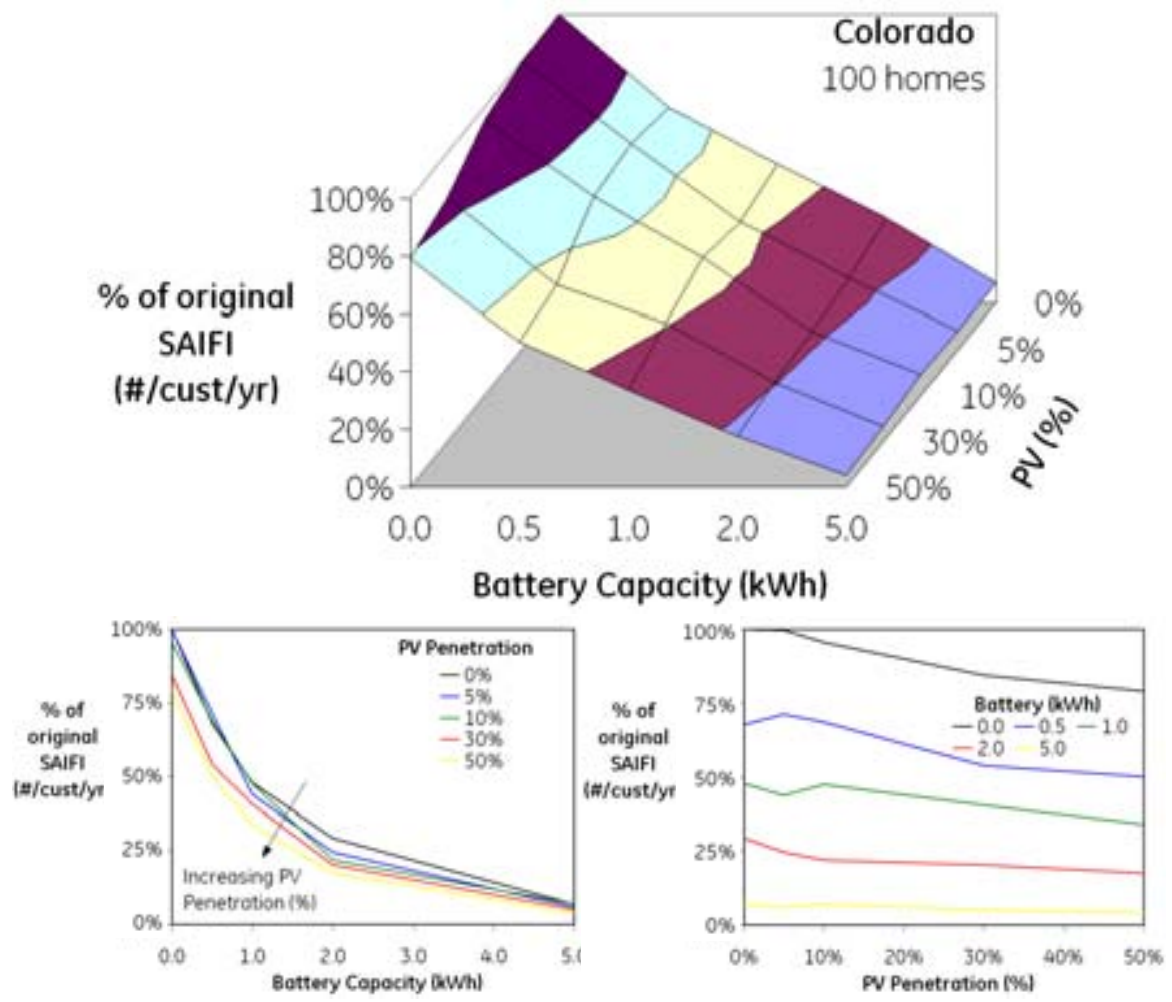

Figure 27. Critical SAIFI for a 100-home community in Golden, Colo.
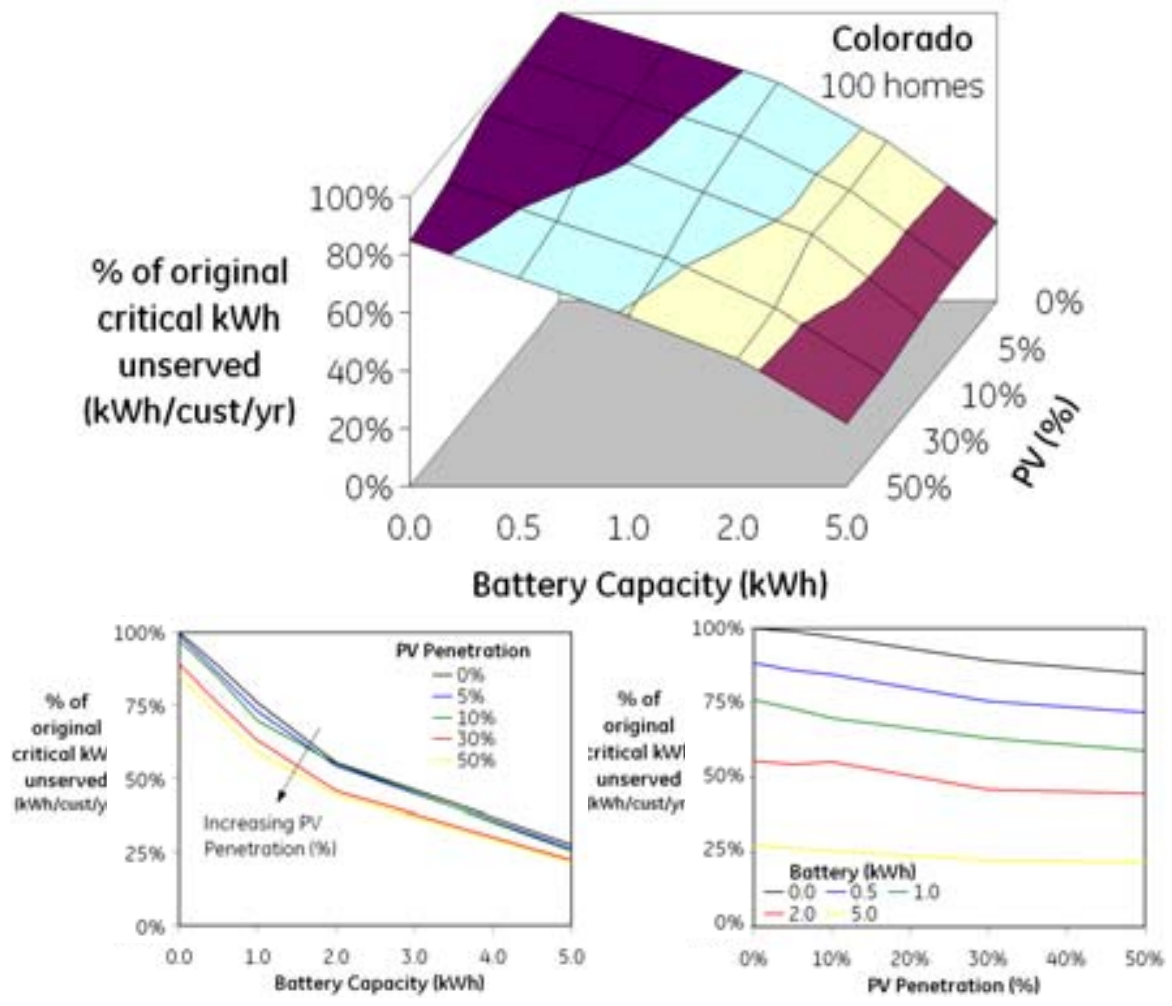

Figure 28. Critical kWh unserved for a 100-home community in Golden, Colo. 
Based on these results, a community with no energy storage $(0 \mathrm{kWh})$ and no PV $(0 \%)$ will experience no enhancement in reliability ( $100 \%$ of original index). As a validation exercise, this was observed for the indices presented in Figure 24. As PV increases, reliability improves. This is suggested by a reduction in the reliability index (decrease in average outage duration and frequency is an improvement in reliability and a reduction in reliability index). Similarly, as the battery capacity increases, reliability improves. As compared with PV penetration level, the enhancement in reliability is more substantial when the size of the battery increases. This is a logical conclusion since a charged battery is available to meet the critical load of a home during an outage at all hours of the day, independent of the presence of sun. Similar trends in reliability enhancement were observed for the other two community sizes and geographic regions.

Based on this study, a significant improvement in these three reliability indices was observed when PV and battery energy storage were deployed at each home within a community. The presence of more than $\sim 5 \mathrm{kWh}$ of battery capacity per home reduced each index to nearly zero (almost a 100\% reduction). The contribution of PV to the improvement in reliability indices was less significant than a battery system, though reliability enhancement was still observed for significant penetration levels. Geographic region had a small impact on the overall results, and the impact of community size could not be fully evaluated due to limitations of the HVAC modeling. 


\section{Gap Analysis}

As in any model, some external effects cannot be captured due to a lack of information or data. For instance, if an interruption is correlated with adverse weather conditions (e.g., clouds, rain, and lightning), insolation may be low and PV may be unavailable. Unless reliability data and insolation data are sourced for the same region and timeframe, the model will not capture this nuance. No data were available that correlated insolation, temperature, and outage statistics. Such data would eliminate the need to assume outages were independent of weather conditions.

The model assumes the immediate availability of the battery and PV to meet critical loads during both short-term and sustained interruptions. The model also assumes that this "alternative supply" of electricity from PV and battery is not interrupted during grid interruptions. These assumptions were necessary in order to model the system.

Distribution reliability statistics were obtained from a single utility in the northeastern United States (Utility A). The statistics for the entire utility were used to represent the outage statistics for the communities considered in this study. Data from additional utilities would facilitate more representative analyses.

The reliability data include a description of the weather condition during each outage event. However, for the same reliability data, there is no data for temperature, wind speed, and insolation. Annual weather and reliability data from a single source for a single region would provide the necessary correlation between weather conditions and PV performance.

The model timeline is broken into 15-minute intervals for both load modeling and reliability modeling for an entire year. This decision was based on the computational power required to model shorter intervals as well as the lack of data available in shorter intervals (i.e. insolation data). The choice of 15-minute intervals for modeling implicitly assumes that any shorter-duration outages or electricity loads cannot be captured. For instance, the model does not account for transient loads due to startup, nor does the model account for the variation in load associated with restarting the grid after an interruption. We anticipate that the loads could substantially exceed the 15-minute rolling load average.

During an outage, the loads deemed non-critical during an outage will eventually become critical. As such, over the duration of an outage, critical loads will tend towards the total load. Essentially, an individual can go without certain appliances for a period of time, but at some point the individual will deem the appliance critical. This has not been accounted for in the model.

The model represents the effectiveness of energy management via the community size parameter. Load averaging over many homes will result in smoother load profiles than load averaging over fewer homes. The model assigns the number of customers affected based on the outage duration chosen from a discrete distribution provided by Utility A. The load profile is not scaled based on the number of customers affected. Instead, we 
assumed that the community size impacts only the smoothing of the load. Therefore, the community size parameter is a suitable proxy for energy management efficacy. One of the key assumptions of this study is the fact that for each outage event, the affected number of customers can reconfigure their loads into critical and non-critical loads, as well as operate as an islanded community, sustaining its critical loads through the use of PV and energy storage. Future research should be performed to identify the technology required to create such functionality within a community.

Further data and analysis could generate a metric of the percentage increase in reliability per $\mathrm{kWh}$ of battery size per $\mathrm{kW}$ of average critical load. This could provide a residential customer with guidance on sizing a battery for enhanced reliability. In addition, enhancing the battery model to include durability and charge/discharge characteristics, and revising its current optimization function (providing energy during outages) could provide a better representation of a battery in a residential community. 


\section{Recommendations for Future Research}

The following headings outline specific future research directions that would enable a more detailed modeling analysis based on the fields of residential load modeling, distribution reliability statistics, and energy systems modeling.

Load reconfiguration technology - We assumed in this study that the loads in a home/community could reconfigure (critical and non-critical) at the onset of an interruption. Identifying the technology and controls needed to perform this function is critical to achieving enhanced reliability using PV systems.

Customer reliability statistics - A single utility's reliability statistics were used in this analysis. Further data and specific information about which customer was affected during an outage event would enhance the accuracy of the simulation. This information will be needed for both utilities and customers in order to quantify the economic benefit of enhanced reliability due to PV systems.

Load profile breakdown-A breakdown of the contributions of various appliances to the overall aggregate load of a home (and community) through a year will be needed before customers and utilities can evaluate the effectiveness of home load control technology for either improving economics or enhancing reliability. This could be done by instrumenting many homes across the country with load data acquisition systems.

Critical loads in communities - Residential customer surveys of appliance usage or appliance feedback to the utility are needed in order to quantify the contribution of each appliance to the total load in a home/community. Identifying the critical loads is paramount to sizing PV arrays and battery storage systems.

Value of lost load - At the cornerstone of quantifying the enhancement in reliability is the understanding of the value of deferring/eliminating an outage. By understanding the economic value of avoiding an outage, utilities and customers will be in a position to invest in residential load controls, PV systems, and energy storage systems.

Availability of load data - A central data repository that consists of all non-proprietary data from this and similar studies, would enable future studies to be performed. Additionally, ease of data acquisition could enable many other, related studies.

Improve DOE 2.2-This DOE tool was used to simulate HVAC loads in a given home for three regions. By enabling 15-minute incremental outputs, higher fidelity models could use DOE 2.2 as a tool. As was mentioned earlier, no coincidence factor was available from DOE 2.2. By aggregating the HVAC loads from multiple homes (i.e., smoothing the HVAC load profile), DOE 2.2 could be used in more and varied applications. 


\section{Conclusions and Recommendations}

The existence of power generation on the "customer side of the meter" creates an opportunity for residential customers to not only enhance the economics of electricity consumption, but also to enhance the reliability of their electric system by islanding during utility outages. As the penetration of PV rises over the coming years, customers will have the opportunity to meet some of their most critical loads during grid interruptions. By developing the technology to reconfigure loads during an outage, individual customers will be afforded the opportunity to enhance the reliability of their electric service through the management of their loads, solar PV, and energy storage devices.

The timing, duration, and number of customers affected by each outage event were obtained for a single utility in 2005 . These data were used to simulate outage events for a community on a distribution feeder. Overall, this technology resulted in a community experiencing fewer outages and outages of shorter duration.

The parameters considered in this analysis include three geographic regions (Golden, Colo., Hanford, Calif., and Sterling, Va.), three community sizes (10 homes, 100 homes, and 1,000 homes), and various combinations of battery capacity ( 0 to $10 \mathrm{kWh}$ ) and solar PV penetration $(0 \%, 5 \%, 10 \%, 30 \%, 50 \%)$. The distribution reliability indices presented in IEEE $1366^{30}$ were adapted to account for the management of energy storage and PV in meeting only the critical loads in each home or community. The enhancement in reliability was quantified in terms of modified reliability indices, pertinent to these types of communities:

- Critical SAIDI - average duration of critical load interruptions.

- Critical SAIFI—average number of interruptions per customer.

- Unserved Critical Load (UCL) - annual unserved critical load (kWh) on a circuit. A significant improvement in these three indices was observed when PV and battery energy storage were deployed at each home within a community. The contribution of PV to the improvement in reliability indices was observable, but less substantial than that of a battery energy storage system. Geographic region had a small impact on the overall enhancement in reliability. The impact of community size has to be reevaluated.

Finally, many specific research topics were identified that will help evaluate the impact of distributed technology on customer reliability with better accuracy. 


\section{References}

${ }^{1}$ IEEE Std 1366, 2003, IEEE Guide for Electric Power Distribution Reliability Indices, IEEE Power Engineering Society.

${ }^{2}$ Bollen, M. Understanding Power Quality Problems: Voltage Sags \& Interruptions. IEEE Press, 2000, p 35.

${ }^{3}$ Ibid. p35

${ }^{4}$ IEEE Guide for Electric Power Distribution Reliability Indices (IEEE Std 1366), page 7.

${ }^{5}$ IEEE, "A Nationwide Survey of Distribution Reliability Measurement Practices," IEEE/PES Working Group on System Design, Paper No. 98 WM 218, in Annex A IEEE 1366.

${ }^{6}$ Schneider, K., Hoad, R. Initial Transformer Sizing for Single-Phase Residential Load. IEEE Transactions on Power Delivery Vol. 7, No. 4, October 1992.

${ }^{7}$ Lee, Y., Etezadi-Amoli, M. An Improved Modeling Technique for Distribution Feeders with Incomplete Information. IEEE Transactions on Power Delivery, Vol. 8, No. 4, 1993.

${ }^{8}$ Noureddine, A., Alouani, A., et al. A New Technique for Short-Term Residential Electric Load Forecasting Including Weather and Lifestyle Influences. Proceedings of the 35th Midwest Symposium on Circuits and Systems, 1992.

${ }^{9}$ Capasso, A., Grattieri, W. A Bottom-Up Approach to Residential Load Modeling. IEEE Transactions on Power Systems. Vol. 9, No. 2, May 1994.

${ }^{10}$ Carpaneto, E., Chicco, G. Probability Distributions of the Aggregated Residential Load, 9th International Conference on Probabilistic Methods Applied to Power Systems, Sweden. 2006.

${ }^{11}$ The Energy Information Administration (EIA) Web site, (a statistical agency of the U.S. Department of Energy), Housing Characteristics Data Tables, http://www.eia.doe.gov/emeu/recs/recs2001/detail_tables.html

12 McMahon, J., Alternative Sectoral Load Shapes for NEMS, Lawrence Berkeley Lab, http://www.onlocationinc.com/LoadShapesAlternative2001.pdf

${ }^{13}$ Crawley Drury B., Hand Jon W., Kummert, Michaël, and Griffith Brent T., Contrasting the Capabilities Of Building Energy Performance Simulation Programs, Ninth International IBPSA Conference Montréal, Canada August 15-18, 2005.

${ }^{14}$ Short, T. Electric Power Research Institute (EPRI) 
15 IEEE, A Nationwide Survey of Distribution Reliability Measurement Practices," IEEE/PES Working Group on System Design, Paper No. 98 WM 218, and Marinello, C. A., "A Nationwide Survey of Reliability Practices," presented at EEI Transaction and Distribution Committee Meeting, Hershey, PA, Oct 20, 1993.

${ }^{16}$ Energy Information Administration - http://www.eia.doe.gov/

${ }^{17}$ http://www.miamiok.org/departmentpages/utilitypages/ut miscpages/applianceusechart . pdf

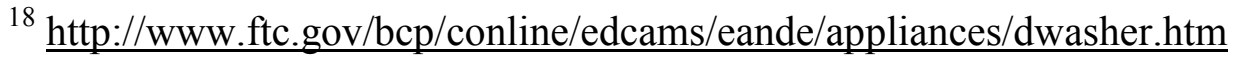

${ }^{19}$ http://www.onlocationinc.com/LoadShapesAlternative2001.pdf

${ }^{20} \mathrm{http}: / / \mathrm{www}$. eia.doe.gov/emeu/recs/recs2001/detail_tables.html

${ }^{21} \mathrm{http} / / /$ www.eia.doe.gov/emeu/recs/recs2001/hc_pdf/usage/hc6-7a_4popstates2001.pdf

${ }^{22}$ Stoll, H. G. Least-Cost Electric Utility Planning, Wiley-Interscience, 1989

${ }^{23} \mathrm{http} / /$ www.ftc.gov/bcp/conline/edcams/eande/appliances/clwasher.htm

${ }^{24}$ IEEE, SAE \& AIAA, 17th Dig. Avion. Sys. Con. (DASC-17), Seattle, WA, Nov. 1998

${ }^{25}$ Stevens J., and Corey, G., A Study of Lead-Acid Battery Efficiency Near Top-ofCharge and the Impact on PV System Design, Sandia National Laboratories, Photovoltaic System Applications Department. http://photovoltaics.sandia.gov/docs/PDF/batpapsteve.pdf

${ }^{26}$ Messenger, R. \& Ventre, J., Photovoltaic Systems Engineering, CRC Press, Chapter 2. 27

http://www.gepower.com/prod_serv/products/solar/en/downloads/gepvp200 datasheet 6 00.pdf

${ }^{28}$ Rauschenbach, H. Solar Cell Array Design Handbook - Principles and Technology of Photovoltaic Energy Conversion, Van Nostrand Reinhold, 1980, ISBN:0-442-26842-4.

29 Markvart, T and Castañer, L. Photovoltaics - Practical handbook of Fundamentals and Applications, Elsevier, 2003, ISBN: 1856173909.

${ }^{30}$ IEEE Std 1366 2003, IEEE Guide for Electric Power Distribution Reliability Indices, IEEE Power Engineering Society. 


\section{REPORT DOCUMENTATION PAGE}

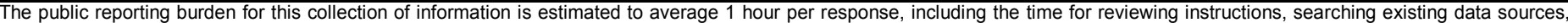

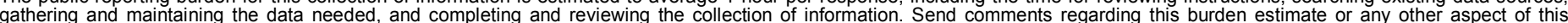

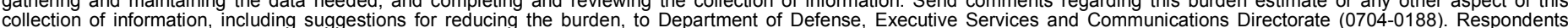

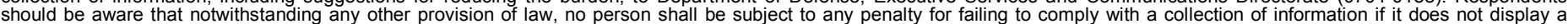

should be aware that notwithstanding

PLEASE DO NOT RETURN YOUR FORM TO THE ABOVE ORGANIZATION.

\begin{tabular}{l|l|l|} 
1. REPORT DATE $(D D-M M-Y Y Y Y)$ & 2. REPORT TYPE & 3. DATES COVERED (FrOm - TO)
\end{tabular}

February 2008

Subcontract Report

4. TITLE AND SUBTITLE

Enhanced Reliability of Photovoltaic Systems with Energy Storage and Controls

5a. CONTRACT NUMBER

DE-AC36-99-G010337

5b. GRANT NUMBER

5c. PROGRAM ELEMENT NUMBER

6. AUTHOR(S)

D. Manz, O. Schelenz, R. Chandra, S. Bose, M. de Rooij, and

J. Bebic

5d. PROJECT NUMBER

NREL/SR-581-42299

5e. TASK NUMBER

PVB7.6401

5f. WORK UNIT NUMBER
7. PERFORMING ORGANIZATION NAME(S) AND ADDRESS(ES)

GE Global Research

1 Research Circle

Niskayuna, NY 12309

9. SPONSORING/MONITORING AGENCY NAME(S) AND ADDRESS(ES)

National Renewable Energy Laboratory

1617 Cole Blvd.

Golden, CO 80401-3393
8. PERFORMING ORGANIZATION REPORT NUMBER

ADC-7-77032-01

12. DISTRIBUTION AVAILABILITY STATEMENT

National Technical Information Service

U.S. Department of Commerce

5285 Port Royal Road

Springfield, VA 22161

13. SUPPLEMENTARY NOTES

NREL Technical Monitor: Ben Kroposki

14. ABSTRACT (Maximum 200 Words)

This report summarizes efforts to reconfigure loads during outages to allow individual customers the opportunity to enhance the reliability of their electric service through the management of their loads, photovoltaics, and energy storage devices.

\section{SUBJECT TERMS}

reliability indices; distribution reliability statistics; residential load modeling; energy storage; residential load controls; photovoltaics; PV; renewable systems interconnection; GE Global Research; National Renewable Energy

Laboratory; NREL

\begin{tabular}{|c|c|c|c|c|}
\hline \multicolumn{3}{|c|}{ 16. SECURITY CLASSIFICATION OF: } & \multirow{2}{*}{$\begin{array}{l}\text { 17. LIMITATION } \\
\text { OF ABSTRACT } \\
\text { UL }\end{array}$} & \multirow{2}{*}{$\begin{array}{ll}\text { 18. } & \text { NUMBER } \\
& \text { OF PAGES }\end{array}$} \\
\hline $\begin{array}{l}\text { a. REPORT } \\
\text { Unclassified }\end{array}$ & $\begin{array}{l}\text { b. ABSTRACT } \\
\text { Unclassified }\end{array}$ & $\begin{array}{l}\text { c. THIS PAGE } \\
\text { Unclassified }\end{array}$ & & \\
\hline
\end{tabular}

19a. NAME OF RESPONSIBLE PERSON

19b. TELEPHONE NUMBER (Include area code) 